\title{
A Conjugate Study of Mean Winds and Planetary Waves \\ Employing Enhanced Meteor Radars at Rio Grande, Argentina $\left(53.8^{\circ} \mathrm{S}\right)$ and Juliusruh, Germany $\left(54.6^{\circ} \mathrm{N}\right)$
}

\author{
D. C. Fritts ${ }^{1}$, H. Iimura ${ }^{1}$, R. Lieberman ${ }^{1}$, D. Janches ${ }^{2}$, and W. Singer ${ }^{3}$ \\ ${ }^{1}$ NorthWest Research Associates, Colorado Research Associates division, Boulder, CO \\ ${ }^{2}$ NASA Goddard Space Flight Center, Space Weather Division, Greenbelt, MD \\ ${ }^{3}$ Leibnitz Institute of Atmospheric Physics, Rostock University, Kuehlungsborn, Germany
}

Corresponding author: D. Fritts

Email: dave@cora.nwra.com

Phone: 303-415-9701, ext. 205

Submitted to Journal of Geophysical Research - Atmospheres

25 May 2011 


\begin{abstract}
Two meteor radars with enhanced power and sensitivity and located at closely conjugate latitudes $\left(54.6^{\circ} \mathrm{N}\right.$ and $\left.53.8^{\circ} \mathrm{S}\right)$ are employed for inter-hemispheric comparisons of mean winds and planetary wave structures. Our study uses data from June 2008 through May 2010 during which both radars provided nearly continuous wind measurements from $\sim 80$ to $100 \mathrm{~km}$. Monthly mean winds at $53.8^{\circ} \mathrm{S}$ exhibit a somewhat stronger westward mean zonal jet in spring and early summer at lower altitudes and no westward monthly mean winds at higher altitudes. In contrast, westward mean winds of $\sim 5-10 \mathrm{~ms}^{-1}$ at $54.6^{\circ} \mathrm{N}$ extend to above $96 \mathrm{~km}$ during late winter and early spring each year. Equatorward monthly mean winds extend approximately from spring to fall equinox at both latitudes, with amplitudes of $\sim 5-10 \mathrm{~ms}^{-1}$ and more rapid decreases in amplitude at $54.6^{\circ} \mathrm{N}$ at higher altitudes. Meridional mean winds are more variable at both latitudes during fall and winter, with both poleward and equatorward monthly means indicating longer-period variability.

Planetary waves seen in the 2-day mean data are episodic and variable at both sites, exhibit dominant periodicities of $\sim 8-10$ and 16-20 days and are more confined to late fall and winter at $54.6^{\circ} \mathrm{N}$. At both latitudes, planetary waves in the two period bands coincide closely in time and exhibit similar horizontal velocity covariances that are positive (negative) at $54.6^{\circ} \mathrm{N}$ $\left(53.8^{\circ} \mathrm{S}\right)$ during peak planetary wave responses.
\end{abstract}




\section{$1 \quad$ Introduction}

Ground-based studies of the mesosphere and lower thermosphere (MLT) have addressed inter-hemispheric differences in mean temperatures and winds, tides, planetary waves (PWs), gravity waves (GWs), and the constituent distributions and microphysical processes that depend on them from mid- to polar latitudes [e.g., Vincent et al., 1988; Avery et al., 1989; Portnyagin et al., 1993a, b, 2006; Fraser et al., 1995; Huaman and Balsley, 1999; Dowdy et al., 2001, 2007;

Chu et al., 2003; Kishore et al., 2003; Riggin et al., 2003; Day and Mitchell, 2010a, b; Iimura et al., 2011]. Similar studies employing satellite data have provided a more uniform global perspective for specific fields, in particular mean stratospheric and MLT temperatures, tidal and PW signatures in MLT temperatures, and polar mesospheric cloud (PMC) distributions that depend critically on mesopause temperature and $\mathrm{H}_{2} \mathrm{O}$ distributions [e.g., Andrews, 1989; Siskind et al., 2003; Hervig and Siskind, 2006; Huang et al., 2006; Bailey et al., 2007; Xu et al., 2007a,b; Mukhtarov et al., 2010].

Inter-hemispheric comparisons of MLT wind fields have been more limited to date. Nevertheless, measurements by HRDI aboard the UARS satellite, TIDI aboard the TIMED satellite, and several meteor and medium-frequency (MF) radars at polar latitudes have revealed inter-hemispheric asymmetries in mean, tidal, and PW wind fields [e.g., Vial, 1989; Burrage et al., 1995; Oberheide et al., 2006; Day and Mitchell, 2010a,b; Iimura et al., 2010, 2011, and references therein]. Mean zonal winds were seen to be stronger over Syowa Station $\left(\sim 69^{\circ} \mathrm{S}\right)$ than over Andenes, Norway $\left(\sim 69^{\circ} \mathrm{N}\right)$ by $\sim 10 \mathrm{~ms}^{-1}$ in summer and winter, while mean meridional winds were seen to be stronger over Syowa in summer, but weaker in winter [Iimura et al., 2011]. Larger non-migrating semidiurnal tides were also seen to occur over the Antarctic than over the Arctic [Iimura et al., 2010]. In contrast, 16-day wave amplitudes and seasonal 
occurrence were found to be very similar between the Arctic and Antarctic at $\sim 68^{\circ} \mathrm{N}$ and S [Day and Mitchell, 2010b], though large interannual variability was also noted.

Our purpose in this paper is to employ new capabilities for conjugate inter-hemispheric MLT wind measurements that recently became available with the installation of a newgeneration meteor radar at the southern tip of South America. The Southern Argentina Agile MEteor Radar (SAAMER) began measurements in May 2008 at Rio Grande, Tierra del Fuego $(\mathrm{TdF})$, Argentina $\left(53.8^{\circ} \mathrm{S}, 67.7^{\circ} \mathrm{W}\right)[$ Fritts et al., 2010, hereafter F10]. This radar is closely conjugate in latitude to a similar meteor radar at Juliusruh (JLR), Germany $\left(54.6^{\circ} \mathrm{N}, 13.6^{\circ} \mathrm{E}\right)$ [Singer et al., 2003]. Wind measurements with each radar are employed for a conjugate study of the mean and PW wind fields measured with the TdF and JLR radars during the 24 months since installation of the TdF radar. A parallel conjugate study of MLT tides at these two sites is provided by Singer et al. [2011]. Descriptions of the radars and our analysis methods are provided in Section 2. Sections 3 and 4 present our measurement results and discussion of the monthly mean winds and PW structures, respectively. A discussion of these results and our conclusions are provided in Sections 5 and 6.

\section{$2 \quad$ Radar Descriptions and Data Analysis}

\subsection{Radar descriptions}

As described by F10, SAAMER on TdF was specifically designed to enable highresolution definition of the large-scale wind field. This is accomplished with a radar frequency and bandwidth of 32.55 and $0.3 \mathrm{MHz}$, respectively, a peak power of $60 \mathrm{~kW}$, and an eightantenna transmitting array using three-element crossed Yagis. This configuration directs the majority of radar power into eight beams centered at an off-zenith angle of $\sim 35^{\circ}$. Five receiver channels enable redundant meteor position definition. A 2-baud, 26- $\mu$ s pulse yields a 2-km range 
resolution that is oversampled by 2 times. The pulse repetition frequency is $2144 \mathrm{~Hz}$. These capabilities yield an average $\sim 20,000$ accepted meteor detections each day (monthly means from $\sim 8,000$ to 24,000 ) at $<50^{\circ}$ zenith angles and $\sim 90 \%$ of these occurring between altitudes of 80 and $100 \mathrm{~km}$. These meteor detections are easily sufficient to define the mean and PW motions of interest here with high precision. Additional details are provided by F10.

The JLR meteor radar employed for this study is identical to the one observing until August 2001 [Singer et al., 2003, 2004a, 2004b, 2005, Szasz et al., 2005]. The radar operates at a frequency of $32.55 \mathrm{MHz}$ with a peak power of $15 \mathrm{~kW}$, a pulse length of $13.3 \mu \mathrm{s}$, and a pulse repetition frequency of $2144 \mathrm{~Hz}$. The system utilizes a three-element Yagi antenna for transmission and a five-antenna interferometer for reception. This antenna configuration determines a meteor location with resolutions of $2 \mathrm{~km}$ in range and $2^{\circ}$ in angle. Daily count rates vary between $\sim 6,000$ and $\sim 13,000$ accepted meteors throughout the year.

\subsection{Data analysis}

Hourly mean zonal and meridional winds were determined by fitting a mean horizontal wind in each 3-km altitude bin centered from 81 to $99 \mathrm{~km}$ for each hour of meteor radial velocity measurements at off-zenith angles between 10 and $55^{\circ}$. These estimates included $\sim 120$ meteors/hour at $90 \mathrm{~km}$ on average, and a minimum count of 5 meteors/hour was required for a valid horizontal wind estimate. Daily and 2-day mean zonal and meridional winds were then computed for each day if a minimum of 12 and 36 hourly wind estimates were available, respectively. Daily means effectively remove tidal motions, while 2-day means minimize contributions from the quasi-2-day wave (2DW), and reduce contributions by the 5-day wave. Missing daily or 2-day means were interpolated from $3^{\text {rd }}$-order spline fits. 
PW contributions to the motion field were identified and analyzed in several ways. An Stransform analysis [Stockwell et al., 1996] was performed to reveal the annual variations of the dominant PW periods at each site. For our purposes here, the S-transform employed a Gaussian full-width half maximum equal to the period evaluated. Given the dominant periods observed, the structure and variability of these motions are examined in greater detail by employing bandpass filters spanning periods of 7-12, 12-24, and 24-50 days, respectively [Isoda et al., 2002; Murphy et al., 2007]. Band pass winds were also employed to compute PW wind hodographs, variances, and horizontal momentum fluxes to aid the interpretation of these motions. Our analyses employing these results are discussed in detail below.

\section{$3 \quad$ Mean Winds}

Zonal and meridional winds from 81 to $96 \mathrm{~km}$ averaged for 2 and 30 days are shown in Figures 1 and 2, respectively. Winds over JLR are shown in the upper panels and winds over $\mathrm{TdF}$ are shown in the lower panels of each figure. The 2-day mean winds exhibit variability on time scales of $\sim 5$ to 30 days about the 30 -day mean winds suggestive of PW and lowerfrequency motions having amplitudes comparable to or exceeding the 30-day mean winds throughout the annual cycle, particularly over TdF. Here we focus on the seasonal behavior of the 30-day mean winds. PW variability will be addressed in greater detail Section 4.

The 30-day mean winds shown in Figure 2 reveal significant qualitative and quantitative

differences between the two sites. Considering first the zonal mean winds ( $\left({ }^{\text {st }}\right.$ and $3^{\text {rd }}$ panels), we see that westward mean winds over JLR descend from the highest altitudes beginning $\sim 1$ month before spring equinox and reach an altitude of $\sim 81 \mathrm{~km}$ approximately a month later. They persist for $\sim 1-2$ months above $\sim 88 \mathrm{~km}$ and for $\sim 4-5$ months below, with maximum 30 -day westward winds of $\sim 25 \mathrm{~ms}^{-1}$. In contrast, summer 30-day westward winds over TdF do not descend from 
above, but appear first at lower altitudes $\sim 1$ month after fall equinox, reach altitudes of $\sim 90 \mathrm{~km}$ within $\sim 2-4$ weeks, and occur only briefly above $\sim 88 \mathrm{~km}$ ( $\sim 1$ month or less), but persist at lower altitudes for $\sim 3-4$ months. 30-day westward winds are also $\sim 10-20 \mathrm{~ms}^{-1}$ stronger during spring 2008 over TdF than observed either year over JLR, achieving a maximum exceeding $40 \mathrm{~ms}^{-1}$ during November and December 2008.

Summer 30-day mean eastward winds over JLR appear at the highest altitudes $\sim 1$ month after spring equinox and descend quickly to $\sim 85-88 \mathrm{~km}$, but not to the lowest altitudes until $\sim 1-2$ months after summer solstice. Unlike mean zonal winds over JLR, eastward 30-day mean winds prevail throughout the year above $\sim 92 \mathrm{~km}$ over $\mathrm{TdF}$. Onsets of summer 30-day eastward winds at higher altitudes over TdF are less well defined, because there are not early spring 30-day westward mean winds at higher altitudes and PW influences on 2-day mean winds are much larger than over JLR (see Figure 1). Nevertheless, they appear to occur $\sim 1-2$ months after spring equinox (see the apparently later transition in 2008 than in 2009) and to descend somewhat more quickly to the lowest altitudes over TdF than over JLR. Magnitudes are similar between sites, and there is discernable but slow variability in the 30-day means at the higher altitudes at each site having a periodicity of $\sim 100$ days.

Eastward 30-day mean winds extend from $\sim 1$ month before fall equinox to after spring equinox throughout the altitude interval measured over JLR, and are even more extended in time over TdF. These fall and winter eastward mean winds are more variable in time at each site than during spring and summer, with apparent periodicities of $\sim 60-90$ days. Also seen is a reduction in eastward mean winds over JLR during January 2009 at higher altitudes and a corresponding strong enhancement during February 2009 accompanying the strongest and most persistent sudden stratospheric warming ever observed [Manney et al., 2009]. 
The onset of persistent equatorward 30-day mean winds (see the $2^{\text {nd }}$ and $4^{\text {th }}$ panels of Figure 2) is highly variable over both sites, varying from as much as $\sim 2$ months before to $\sim 1$ month after spring equinox during our observation period. 30-day mean equatorward winds persist for $\sim 5-6$ months over both sites, with the onset and cessation over each site apparently strongly influenced by PW activity extending from $\sim$ fall to spring equinox. 30-day mean equatorward winds exceed $10 \mathrm{~ms}^{-1}$ below $\sim 90 \mathrm{~km}$ near summer solstice over JLR, but are somewhat weaker and extend to higher altitudes near summer solstice over TdF. 30-day mean meridional winds from fall to spring equinoxes are seen to be much more variable over both sites, with weak poleward seasonal means, poleward and equatorward 30-day means over both sites, and greater apparent variability over TdF.

\section{$4 \quad$ Planetary Waves}

\subsection{S-transforms}

A more quantitative perspective on zonal and meridional wind variability on PW time scales is provided in Figure 3 with S-transforms of the 2-day mean winds at 84 and $96 \mathrm{~km}$ (left and right) over JLR and TdF (top and bottom). These exhibit significant differences between the two altitudes at each site. Strong seasonal responses are seen simultaneously at 84 and $96 \mathrm{~km}$ in a number of cases, but there are other strong responses at one altitude that are not significant at the other (especially in the zonal component over TdF). Also seen is a tendency for greater temporal confinement of the strong PW responses over JLR (top panels), with the strongest responses extending from slightly before winter solstice into February ( $\sim 2$ months after winter solstice). Responses over TdF (bottom panels), in contrast, begin $~ 1-2$ months before winter solstice, extend $\sim 4$ months or more beyond winter solstice, especially in the zonal motions and at $96 \mathrm{~km}$, 
and appear to be more episodic and less coherent among different PW periods. Specific examples of PW responses over JLR include:

1) coherent maxima at 84 and $96 \mathrm{~km}$ that are most pronounced in the meridional component beginning in January 2009 , appear first at a period of $~ 16$ days, and rapidly yield stronger maxima at periods from $\sim 8-12$ days; and

2) a similar event beginning in late November of 2009 , again with an initial period of $\sim 16$ days, but now with maxima in the meridional component at $84 \mathrm{~km}$ and in the zonal component at $96 \mathrm{~km}$; a subsequent maximum again extends to a period of $\sim 8-12$ days accompanying the attainment of the strong maximum at $\sim 16$ days; additional maxima occur at PW periods of $\sim 10$ and 20 days (in the meridional and zonal components, respectively) 1-2 months later, suggesting a coupling of modes and/or evolution of the maximum response to shorter periods based on the zonal behavior at $96 \mathrm{~km}$.

Corresponding PW or longer-period responses over TdF include:

3) a relatively discrete maximum at $96 \mathrm{~km}$ at an initial period of $\sim 16$ days in the meridional component in early June 2008, with rapid successive (and stronger) maxima in the zonal component at periods of $\sim 8-10,20$, and 40 days quickly thereafter;

4) additional isolated maxima from June to August 2008 at a period of $\sim 10$ days in the meridional component at $84 \mathrm{~km}$ and in the zonal component at $96 \mathrm{~km}$, and at a period of $\sim 16$ days in the meridional response at $96 \mathrm{~km}$; and

5) relatively isolated maxima at periods of $\sim 30-40$ and 16-20 days from June-December 2008 and from May-September 2009 seen primarily in the zonal winds at higher altitudes. 
Observed PW periods are generally consistent with the normal modes expected from classical theory assuming a stationary, isothermal, and inviscid atmosphere [Volland, 1988; Forbes, 1995]. Normal modes having the gravest zonal wavenumber $\mathrm{s}=1$ are expected (and observed) to exhibit a range of periods from $\sim 5$ days to $\sim 16$ days, with westward phase speeds varying inversely with the period. However, their latitudinal and vertical structures and periods may differ significantly from the idealized modal structures due to the variations of mean winds and temperatures with latitude and altitude [Salby, 1981a,b].

PWs appear in the MLT in number of ways. Evidence suggests that 5-day and 16-day waves arising at lower altitudes in the winter hemisphere propagate directly into the winter MLT, but may also appear in the summer MLT due to propagation from the winter hemisphere at altitudes above the summer mesospheric jet [Forbes et al., 1995; Miyoshi, 1999; Riggin et al., 1999]. PW westward phase speeds are comparable to westward mean winds in the summer stratosphere and mesosphere, suggesting possibilities for generation or amplification by barotropic, baroclinic, or optimal instabilities as well as PW-mean flow interactions [e.g., Simmons et al., 1978; Charney and Straus, 1980; Hirooka and Hirota, 1985; Smith, 1985; Randel et al., 1987; Farrell, 1988; Farrell and Ioannou, 1992]. PWs have also been suggested to arise from in situ excitation in the MLT due to differential momentum deposition in the MLT accompanying modulation of GW sources or filtering at lower altitudes [Williams and Avery, 1992; Forbes et al., 1995; Smith, 2003].

While longer-period oscillations are seen in the MLT at equatorial and higher latitudes [e.g., Eckermann et al., 1997; Luo et al., 2001], these are likely not PW normal modes, given the observed phase structures and expectations of strong influences by mean winds at these periods [see Forbes, 1995, and references therein]. Instead, they appear to accompany longer-period 
oscillations, e.g., the Madden-Julien oscillation [Madden and Julien, 1994], which modulate tropical convection in the troposphere.

Of the various PW modes anticipated by theory, we thus expect the most prominent to be the "10-day" and "16-day" PWs within the frequency band displayed in Figure 3, based on observations at many sites. Our S-transform results are consistent with this, and with the expectation of strong wave-wave and wave-mean flow interactions and the rapid temporal variability of the wind fields accompanying these various interactions.

\subsection{Band pass results}

In order to determine which PW periods contribute the dominant zonal and meridional wind responses having continuity in altitude, we examine the S-transform results as functions of altitude for periods of $8,10,12,16,20,30$, and 40 days. The largest and most coherent responses occur at periods of 10, 16, 20, and 40 days, and S-transform amplitudes for these periods are shown in Figure 4 as functions of altitude. Examination of these fields reveals the following:

1) 10-day oscillations (maxima $\sim 15-25 \mathrm{~ms}^{-1}$ ) over JLR in January 2009 and from

December 2009 to February 2010 and over TdF during July and August 2008 at higher and lower altitudes, respectively, during September and October 2008 at all altitudes, and episodically over a range of altitudes from July 2009 to April 2010;

2) 16-day oscillations over JLR during September 2008, from November 2008 to February 2009 (with maxima of $\sim 10-15 \mathrm{~ms}^{-1}$ ), and from November 2009 into February 2010 and over TdF from June to October 2008, from April to September 2009, and episodically from December 2009 to May 2010; 
3) 20-day oscillations (maxima $\sim 8-16 \mathrm{~ms}^{-1}$ ) over JLR during November 2008 to January 2009, during September 2009, and from December 2009 to February 2010 and over TdF sporadically from June to December 2008 and May to September 2009, during December 2009, and during April and May 2010; and

4) 40-day oscillations (maxima $\sim 10-12 \mathrm{~ms}^{-1}$ ) over TdF during June and July 2008 and from April to September 2009, with much weaker responses at lower altitudes over JLR.

The dominant S-transform responses suggest that $\sim 8$-10 day and $\sim 16-20$ day PWs account for the major variability of the MLT wind field. They also reveal that longer-period oscillations make important contributions, as seen clearly in the $\sim 30-40$ day mean wind variations between fall and spring equinoxes in Figure 1 (especially over TdF) and the $\sim 90$-day variations during the same periods in Figure 2. To examine the amplitudes and phase structures of the motions that are most easily identified as PWs more closely, we display in Figures 5 and 7 contours of the zonal and meridional winds over JLR and TdF (at top and bottom) for 7-12 and 12-24 day band passes. Shown in Figure 6 are the band-passed zonal and meridional amplitudes at 3-km intervals from 81 to $96 \mathrm{~km}$ for the 7-12 and 12-24 day band passes over JLR and TdF (at top and bottom, respectively) for fall and winter seasons over JLR and for the full annual cycle over TdF, to more easily display relative phases and amplitudes within and between these PW bands.

\subsection{1 $\sim 8$-10 day PWs}

Considering first the 7-12 day band pass results shown in Figure 5 (chosen to largely exclude influences of the 6.5-day PW), we see that the $\sim 10$-day PWs over JLR exhibit distinct late-fall to early-winter maxima extending over $\sim 2-3$ months during the two years studied. These amplitudes are also displayed in the upper panels of Figure 6 at each altitude for the two fall and 
winter seasons with the wind components overlaid to more easily identify their relative phases. We note that these band-passed amplitudes exhibit both smoothed temporal variability and somewhat smaller maximum amplitudes (now $\sim 20 \mathrm{~ms}^{-1}$ ) than seen in the S-transforms in Figure 3. This is expected for the relatively narrow band passes necessary to distinguish between closely spaced PW periods examined here. Also seen clearly is the commencement of the $\sim 10$-day PW earlier in the zonal component, with comparable meridional amplitudes lagging by $\sim 20-30$ days until the maximum amplitudes in late December 2008 and January 2009 are approached. Phase structures exhibit downward progression (upward propagation) with a vertical wavelength of $\sim 60$ $\mathrm{km}$ in both components during the development of this event, with the vertical wavelength increasing more strongly in the zonal than in the meridional component as the maximum amplitudes are achieved. The zonal and meridional components are nearly in phase during the initial growth of this response, with phases more nearly in quadrature as the peak response is attained in January (see the upper panels of Figure 6). At this time, the wind vector rotates counter-clockwise with time and altitude.

The major 10-day PW response during the second year exhibits an earlier development in both components, a minimum in the zonal response near winter solstice, and a resurgence to the largest $\sim 10$-day PW amplitude seen over JLR during January and February 2010 (exceeding $20 \mathrm{~ms}^{-1}$ at the lowest altitudes in early February). The zonal phase is nearly constant with altitude at early stages, has a vertical wavelength approaching $\sim 60 \mathrm{~km}$ during the strong amplitude growth (as seen in the strong meridional component in the first event) and thereafter. Meridional phase variations remain nearly uniform in altitude throughout this event, with a near quadrature relation between components now seen at the highest rather than the lowest altitudes and a more nearly in-phase relation at lower altitudes and later times (see Figure 6). 
In contrast to the $\sim 10$-day PW responses over JLR, those over TdF are more diffuse, less consistent between the zonal and meridional components, and more variable throughout the annual cycle and in the PW period (see the third panels of Figures 5 and 6). Maximum amplitudes of $\sim 10-15 \mathrm{~ms}^{-1}$ occur in the zonal component at higher altitudes in June and July and from late September into October 2008, at lower altitudes during November and December 2008, briefly in July 2009, and in February and April 2010. Among the stronger events, meridional amplitudes are smaller in most cases, but are comparable to, or exceed, zonal amplitudes in July and August 2008, February and March 2009, and April 2010. Surprisingly, the largest zonal amplitudes from October to December $2008\left(\sim 15 \mathrm{~ms}^{-1}\right)$ coincide with meridional amplitudes $\sim 3$ 5 times smaller, with a similar amplitude disparity seen during February 2010 at lower altitudes. Where amplitudes are well defined, phase variations are largely consistent with those noted in the discussion of responses over JLR (especially in early 2010), with more nearly in-phase (antiphase) responses over JLR (TdF), respectively (see, e.g., June, July, and October 2008 at higher altitudes and February and April 2010).

\subsection{2 $\sim 16-20$ day $P W s$}

Amplitude and phase structures for PWs having periods of $\sim 16-20$ days using a 12-24 day band pass are shown as contour plots in Figure 7 and as time series at specific altitudes in the $2^{\text {nd }}$ and $4^{\text {th }}$ panels of Figure 6 . These results exhibit similar seasonal variability to that seen for $\sim 8$-10 day PWs, with the major responses over JLR largely confined to fall and winter seasons, but with those over TdF more widely distributed throughout each year. The 12-24 day band pass results exhibit greater apparent variability of the PW periods than seen in the 7-12 day band pass, however. Two factors that likely contribute to this variability in observed PW periods in the $\sim 12$ 24 day band pass include 1) their slower phase speeds and greater potential for Doppler shifting 
by temporally-varying mean zonal winds and 2) the possible presence of additional PW modes, depending on the propagation environment [see Forbes, 1995, Figure 3].

The first interval showing enhanced $\sim 16-20$ day amplitudes over JLR extends from $\sim$ October 2008 to February 2009 (see the upper panels of Figure 7 and the $2^{\text {nd }}$ left panel of Figure 6). Given the observed variability in amplitudes and phase structures (as seen in the 7-12 day band pass winds over JLR during this time), these fields likely represent several successive or superposed responses in reality. Zonal and meridional winds at higher altitudes are nearly in phase as amplitudes increase in October and November and suggest a period of $\sim 12-15$ days. In December, however, the wind components suggest a longer period in the zonal component, a superposition of longer and shorter periods in the meridional component, and an evolution towards a more nearly anti-phase relation. Longer-period motions persist in the zonal component throughout January, yielding a nearly in-phase relation in mid February 2009. Both components exhibit phase descent with time, except for the meridional component in late December and early January, where phases appear nearly constant in altitude. The more gradual descent of phase slopes seen in the zonal wind during January suggests a vertical wavelength of $\sim 40 \mathrm{~km}$.

The second interval exhibiting significant $\sim 16-20$ day amplitudes over JLR extends from November 2009 to February 2010. As seen in the first interval, there is evidence of a possible superposition of modes, given the lack of uniformity of the phase structures with time and between the two wind components. Initial amplitude growth appears to occur first at lower altitudes, with the largest amplitudes in the zonal winds at higher altitudes during December and at lower and middle altitudes in January and February (each exceeding $20 \mathrm{~ms}^{-1}$ ). Phase variations exhibit downward progression (suggesting upward propagation) during December, with vertical wavelengths of $\sim 60 \mathrm{~km}$ initially, and become more nearly constant with altitude by late January. 
Variations of phase with altitude and time also imply varying phase relations between the wind components. The early evolution of the second event exhibits a nearly quadrature relation between zonal and meridional winds during November and December 2009 at lower altitudes, but a more nearly in-phase relation at higher altitudes as the maximum amplitudes are achieved. Apparent superpositions thereafter yield more jumbled phase structures, with little coherence in altitude or time, except for the strong $~ 15$-day response from mid January to mid February.

Amplitudes and phases of the $\sim 16-20$ day PWs over TdF are shown with contour plots in the lower panels of Figure 7 and at specific altitudes in the lower panel of Figure 6. As seen over JLR, the largest responses occur primarily during fall and winter ( $\sim$ April through September), but also extend into spring (October and November) at lower and higher altitudes, respectively. Unlike JLR, significant amplitudes are also observed during summer, consistent with the behavior noted for the $\sim 8-10$ day amplitudes observed over TdF. In contrast with the $\sim 16-20$ day PWs seen over JLR, but consistent with the $\sim 8$-10 day PWs seen over TdF, the $\sim 16-20$ day PWs seen over TdF during both fall/winter seasons exhibit a largely anti-phase relation between the wind components wherever larger amplitudes are observed, except in June 2008. This occurs despite the apparently more temporally variable PW amplitudes, periods, and phase structures over TdF at these times. This variability suggests more significant PW superpositions within this band pass than over JLR during the comparable northern hemisphere seasons. Given this, it is even more surprising that the phases of the zonal and meridional components are so highly anticorrelated during these times.

\subsection{3 wind hodographs}

Hodographs of the monthly 7-12 day band-passed winds at 81 and $96 \mathrm{~km}$ are shown in Figure 8 for the fall and winter seasons over JLR and TdF. As noted above, maximum responses 
are seen over JLR during December, January, and February in each season. The $\sim 8-10$ day vector winds are seen to remain small in December 2008, but to increase with time at both altitudes during January 2009 and with the same counter-clockwise rotation and approximate quadrature between components and the two altitudes. The major axis of the velocity field later in January at both altitudes is approximately NNE-SSW. Vector winds decay during February, with the same sense of rotation and phase variation in altitude seen in January, but now with an orbital ellipse having a major axis aligned NE-SW indicating more nearly comparable amplitudes in the two components accompanying amplitude decay.

The $~ 8-10$ day vector winds over JLR during December 2009 exhibit large amplitudes (and counter-clockwise rotation) early in the month, decay thereafter, and appear to be largely unconnected to the larger responses that follow. An apparently separate event emerging in January exhibits significant amplitude growth throughout the month, with counter-clockwise rotation of the wind vector at $96 \mathrm{~km}$, but a clockwise rotation of the wind vector at $81 \mathrm{~km}$ that appears to reverse near the end of the month. This event exhibits a decay in February, with counter-clockwise rotation while amplitudes are large and an increased in-phase relation among components as seen in early 2008 . Thus, there are significant similarities between the major $\sim 8$ 10 day PW events during fall and winter seasons over JLR during the two seasons observed.

Referring now to the $\sim 8$-10 day responses over TdF shown in the lower panels of Figure 8, we note a very different PW morphology throughout austral fall and winter. While there are individual months that exhibit winds comparable to those seen over JLR, there are no consistent seasonal maxima during the intervals displayed. Significant winds (approaching $\sim 20 \mathrm{~ms}^{-1}$ ) occur primarily at the higher altitudes during June, July, and October 2008, with weaker winds at lower altitudes and other times, including the months displayed for 2009. There are, nevertheless, 
common features in the responses over JLR and TdF. The tendencies for correlations between the wind components appear generally anti-symmetric about the equator, with largely positive correlations at northern latitudes and negative correlations at southern latitudes. These tendencies also exhibit some consistency in altitude and time. In terms of consistent seasonal variations in PW amplitudes, however, the 7-12 day band pass responses have very little in common between JLR and TdF.

Hodographs of the monthly 12-24 day band-pass winds at 81 and $96 \mathrm{~km}$ are shown in Figure 9 for the fall and winter seasons over JLR and TdF. As noted in the discussion of Figures 5-7 and seen for the 7-12 day band-pass hodographs above, distinct maxima over JLR occur from $\sim$ November to February each year. In most cases, there is a clear counter-clockwise rotation of the wind vector, except where evidence of PW superposition is observed. There is also a weak tendency for positive correlations between zonal and meridional winds during the growth phases of these events, with less distinct correlations during the decay phases.

As seen for the 7-12 day band pass hodographs, those for the 12-24 day band pass in Figure 9 reveal a very different PW morphology over TdF in austral fall and winter than seen over JLR. While there are individual months that exhibit winds comparable to those seen over JLR, maxima appear to occur during late fall and winter, and there is a tendency for negative correlations between zonal and meridional winds (and an anti-symmetric response about the equator), there is also significantly greater amplitude and phase variability with altitude and time over TdF than seen over JLR. This suggests a more complex superposition of PWs at southern than northern latitudes during fall and winter seasons.

\subsection{4 horizontal velocity variances}


Horizontal velocity variances in the 7-12 day and 12-24 day PW band passes are shown over JLR in the upper left panels and over TdF in the lower left panels of Figure 10. These illustrate much more clearly than the S-transforms and band pass winds the temporal and altitude localization of PW activity within each band pass. The upper panels reveal that PW activity is highly localized from $\sim$ November to February each year over JLR, and that significant variances in the 12-24 day band pass typically precede or accompany enhanced variances in the 7-12 day band pass and are also coincident in altitude. Surprisingly, the variances in the two bands also have comparable magnitudes during the dominant responses in January and February 2010, 300 $\mathrm{m}^{2} \mathrm{~s}^{-2}$, suggesting peak 30-day mean RMS amplitudes of $\sim 13 \mathrm{~ms}^{-1}$ assuming comparable amplitudes in both components.

PW activity over TdF is more broadly distributed throughout the year, but with primary maxima typically occurring during fall and winter. Maximum variances over TdF are $\sim 200 \mathrm{~m}^{2} \mathrm{~s}^{-2}$ in the 12-24 day band pass and $\sim 20 \%$ smaller in the 7-12 day band pass. Unlike the PW fields over JLR, the variances in the two band passes exhibit few obvious correlations, though the maxima in the two band passes occurring in mid to late June 2008 at higher altitudes could indicate a link, with the 12-24 day band pass response preceding the 7-12 day band pass, as seen over JLR. A similar link is suggested between the 12-24 day band pass variance maximum during September and October 2008 and the successive 7-12 day band pass variance maximum in early October 2008 at somewhat higher altitudes.

\subsection{5 horizontal momentum fluxes}

Horizontal momentum fluxes implied by the correlations between wind components seen in the hodographs discussed above are shown continuously in time and altitude in the right panels of Figure 10 in the same format as the band pass variances at left for easy reference. 
Comparing these panels, we see immediately that the variance maxima seen in both band passes over JLR coincide closely with positive momentum flux maxima.

Identical arguments about the correlations between PW variances and momentum fluxes over $\mathrm{TdF}$ can be made by examination of the corresponding variances and momentum fluxes shown in the two PW bands in the lower panels of Figure 10. In this case, however, the most conspicuous negative momentum flux maxima seen at lower right correlate strongly with the variance maxima in each PW band pass seen at lower left. As seen over JLR, mean momentum fluxes over TdF from mid-spring through mid-summer are weakly positive and of the opposite sign to the strong fall and winter responses.

\section{Discussion}

As seen above, mean eastward and westward winds over JLR and TdF in winter and summer are comparable at lower altitudes, with peak magnitudes of $\sim 20-30 \mathrm{~ms}^{-1}$, with slightly larger maxima over TdF, apart from the anomalous peak over JLR in February 2009 following the largest stratospheric warming on record. At higher altitudes, monthly mean winds are predominantly eastward over JLR and entirely eastward over TdF, with summer maxima more distinct over JLR and magnitudes of $\sim 30 \mathrm{~ms}^{-1}$ or greater over both sites. Comparing these mean winds with those measured over Andenes $\left(69^{\circ} \mathrm{N}\right)$ and Syowa $\left(69^{\circ} \mathrm{S}\right)$ by Iimura et al. [2011] from 1999 to 2010, we see that summer westward winds are comparable at the northern latitudes and stronger at the higher southern latitude, but that winter eastward winds are significantly weaker at the higher latitudes in each hemisphere.

Mean equatorward winds in summer were seen in our discussion above to be stronger over JLR $\left(>10 \mathrm{~ms}^{-1}\right)$ than over TdF at lower altitudes, but to be centered at somewhat higher altitudes over TdF. Mean meridional winds in winter, in contrast, are weak and poleward in the 
seasonal means at JLR and TdF, but highly variable in the monthly means. Comparing these results with those of Iimura et al. [2011], we see that the equatorward summer winds over JLR are larger than over Andenes, but that this latitudinal gradient is reversed at southern latitudes, with equatorward winds somewhat larger over Syowa than over TdF, but also much more confined in altitude. Mean meridional winds in winter at higher latitudes (Andenes and Syowa) are likewise weak in both hemispheres. But both also exhibit a reversal from mean poleward motions at lower altitudes to mean equatorward motions at higher altitudes, in sharp contrast with the winds over JLR and TdF.

PW results presented above are generally consistent with previous studies of the "10-day" and "16-day" waves at middle and high latitudes. Large PW amplitudes are largely confined to fall and winter seasons, but smaller amplitude responses occur throughout the year over both JLR and TdF. Large amplitudes in both bands are also more narrowly confined to late fall and early winter over JLR than over TdF, and more so in the meridional than in the zonal winds at both sites. The former appears to differ from the 16-day wave results of Day and Mitchell [2010b] for Rothera and Esrange at somewhat higher latitudes, but may be a further indication of the significant inter-annual variability noted in both studies. The latter is consistent with the occurrence statistics reported by Murphy et al. [2007] for their 8-16 day band pass results over Davis, Antarctica. Maximum amplitudes of the $~ 16$-day wave in our 12-24 day band pass exceed $20 \mathrm{~ms}^{-1}$ at both JLR and TdF, and are thus somewhat larger than seen by Day and Mitchell [2010b] over Esrange $\left(68^{\circ} \mathrm{N}\right)$ and Rothera $\left(68^{\circ} \mathrm{S}\right)$ and by Murphy et al. [2007] over Davis $\left(69^{\circ} \mathrm{S}\right)$. Our maximum amplitudes are $\sim 100 \%$ larger than observed at comparable northern latitudes by Mitchell et al. [1999] over Sheffield $\left(54^{\circ} \mathrm{N}\right)$, by Forbes et al. [1995] over Obninsk $\left(54^{\circ} \mathrm{N}\right)$ and Saskatoon $\left(52^{\circ} \mathrm{N}\right)$, and by Luo et al. [2002] at multiple locations. Maximum amplitudes of the 
$\sim 10$-day wave are $\sim 20-50 \%$ smaller than those of the $\sim 16$-day wave. These differences may not be significant, however, given the different radars and band pass methods employed for each study. Maximum amplitudes of the $\sim 10$-day wave in our study also exceed $20 \mathrm{~ms}^{-1}$, but are typically somewhat smaller than for the $\sim 16$-day wave.

Where PW amplitudes are large and the rotation of the wind vector is well defined, the predominant sense of rotation is counter-clockwise over JLR. This is consistent with that seen for the 16-day over Sheffield by Mitchell et al. [1999]. Orbital ellipses are less well defined, in general, over TdF, and may be an indication of more significant PW superpositions or interactions at southern latitudes.

The temporal behavior of the significant PW responses in the S-transforms displayed in Figure 3 suggests somewhat different morphologies of, and/or nonlinear interactions involving, the PWs in each hemisphere. Strong isolated responses occur from $\sim$ November to February each year over JLR, each including simultaneous responses at different periods or events that appear to arise having one period, but quickly evolve to another. Such coupled responses may be an indication of common or evolving sources of the various PW responses. We also note, however, that more complex coupling among different components of the motion field may be suggested by smaller-amplitude motions over JLR, as discussed further below. S-transforms for TdF, in contrast, exhibit multiple maxima that often appear to evolve through more complex interactions among several periods, though at smaller amplitudes than the dominant responses over JLR. Indeed, these apparent links among different responses in the S-transforms appear very similar to those seen in the spectrograms shown by Mitchell et al. [1999] over Sheffield. Additional evidence of possible PW interactions is provided by the lack of spatial coherence of the 16-day wave fields observed simultaneously at multiple Northern Hemisphere locations by Luo et al. 
[2002]. Thus, while the dominant responses appear to have somewhat different character in the two hemispheres, the underlying dynamics at smaller amplitudes appear to be a common feature of both.

To the extent that large momentum fluxes are indicative of significant PW-mean flow interactions, these results may provide clues to the character of these interactions and the potential for barotropic and/or baroclinic instability of the mean flow as the source of the observed PWs. Zonal mean winds in the Global Empirical Wind Model (GEWM) indicate curvature of the zonal wind on the poleward flanks of the wintertime midlatitude jet [Portnyagin et al., 2004]. At JLR, positive momentum fluxes in the wintertime months are consistent with the typical SW-NE alignment of large-scale, amplifying perturbations. Thus, the PW variances, fluxes, and climatological mean winds at JLR fit into a model of barotropic instability.

Likewise, the strong negative momentum fluxes during late winter at $\mathrm{TdF}$, and the climatological wind pattern, are consistent with a southern hemisphere version of the instability. Momentum flux estimates at single sites are not sufficient to fully diagnose PW-mean flow interactions, however. This requires definition of the mean wind and temperature fields and a more complete characterization of the various contributions to the Eliassen-Palm flux as functions of latitude and time than can be accomplished with discrete wind measurements. We also note that our negative momentum fluxes over TdF are of the same sign as the mean over Davis during Austral winter [Murphy et al., 2007], but that the mean positive momentum fluxes seen over Davis from September through December are advanced by $\sim 2$ months relative to our more limited observations. 


\section{Summary and Conclusions}

We employed meteor radars at approximately conjugate latitudes (Juliusruh, Germany, $54.6^{\circ} \mathrm{N}$, and Rio Grande, Argentina. $53.8^{\circ} \mathrm{S}$ ) for inter-hemispheric comparisons of mean winds and planetary wave structures from June 2008 to May 2010 for which coincident and nearly continuous data were available.

Differences in mean winds between the two sites include the following:

1) westward monthly mean winds extending to higher altitudes over JLR than over TdF during early spring each year,

2) significantly stronger westward monthly mean winds from $\sim 81-90 \mathrm{~km}$ over TdF during late spring 2008 than seen over JLR either year,

3) comparable or larger eastward monthly mean winds during fall and winter (greater by 5$20 \mathrm{~ms}^{-1}$ ) over TdF than over JLR, except for an anomalously strong eastward monthly mean wind over JLR in February 2009 accompanying the strongest and most prolonged stratospheric warming on record [Manney et al., 2009],

4) equatorward monthly mean winds during late spring and early summer at each site that achieve amplitudes of $\sim 5-10 \mathrm{~ms}^{-1}$ at lower altitudes, with slightly larger amplitudes over JLR and amplitudes decaying more slowly at higher altitudes over TdF, and

5) meridional mean winds during fall and winter that are weakly poleward (except during the January 2009 stratospheric warming) and more variable than during spring and summer because they are significantly impacted by PW and lower-frequency oscillations. Both JLR and TdF exhibit PW and longer-period oscillations extending from $\sim 8-40$ days. Shorter-period PWs were specifically excluded from this analysis. Dominant PW responses occur at periods of $\sim 8-10$ and 16 days over both sites, with these motions more strongly confined 
to late fall and early winter months over JLR than over TdF. These responses are more nearly coincident over JLR and more typically sequential over TdF, suggesting different source and/or interaction dynamics in the two hemispheres. Horizontal momentum fluxes evaluated by the two radars are typically strongly positive (negative) over JLR (TdF) during large PW responses, suggestive of sources due to barotropic instability. However, these radar wind measurements by themselves are insufficient to diagnose the potential PW-mean flow dynamics fully, and an expanded study employing satellite data is envisioned for this purpose.

To investigate the possible indications of PW-mean flow interactions further, the behavior at JLR and TdF must be placed into a global-scale context. Satellite winds from TIMED, and temperatures from TIMED or EOS/MLS, will be used to define the PW fields at these and other latitudes in a follow-on to the present study. The global extent of these data will enable calculation of meridional gradients of PW momentum fluxes, and their effects on the mean flow. Satellite data will also allow the role of heat fluxes to be examined.

Acknowledgments. Research described here was performed under NSF grant ATM-0634650. The authors are also very grateful for the valuable support of personnel at Estacion Astronomica Rio Grande (EARG) for their assistance with the operations and maintenance of SAAMER. 


\section{$7 \quad$ References}

Andrews, D. G., 1989: Some comparisons between the middle atmosphere dynamics of the southern and northern hemispheres, Pure Appl. Geophys., 130, 213-232.

Avery, S. K., R. A. Vincent, A. Phillips, A. H. Manson, and G. J. Fraser, 1989: High-latitude tidal behavior in the mesosphere and lower thermosphere, J. Atmos. Terres. Phys., 51 (7/8), $595-608$

Bailey, S. M., A. W. Merkel, G. E. Thomas, and D. W. Rusch, 2007: Hemispheric differences in Polar Mesospheric Cloud morphology observed by the Student Nitric Oxide Explorer, J. Atmos. Solar-Terres. Phys., 69(12), 1407-1418.

Burrage, M. D., D. L. Wu, W. R. Skinner, D. A. Ortland, and P. B. Hays, 1995: Latitude and seasonal dependence of the semidiurnal tide observed by the high-resolution Doppler imager, J. Geophys. Res., 100(D6), 11,313-11,321.

Charney, J. G., and D. M. Straus, 1980: Form-drag instability, multiple equilibria and propagating planetary waves in baroclinic, orographically forced, planetary wave systems, J. Atmos. Sci., 37(6), 1157-1176.

Chu, X., C. S. Gardner, and R. G. Roble, 2003: Lidar studies of interannual, seasonal, and diurnal variations of polar mesospheric clouds at the South Pole, J. Geophys. Res., 108(D8), 8447, doi:10.1029/2002JD002524.

Day, K. A., and N. J. Mitchell (2010a), The 5-day wave in the Arctic and Antarctic mesosphere and lower thermosphere, J. Geophys. Res. (Atmospheres), 115, 1109-, doi:10.1029/2009JD012545.

Day, K. A., and N. J. Mitchell (2010b), The 16-day wave in the Arctic and Antarctic mesosphere and lower thermosphere, Atmos. Chem. \& Phys., 10, 1461-1472. 
Dowdy, A., R. A. Vincent, K. Igarashi, Y. Murayama, and D. J. Murphy (2001), A comparison of mean winds and gravity wave activity in the northern and southern polar MLT, Geophys. Res. Lett., , 28, 1475-1478, doi:10.1029/2000GL012576.

Dowdy, A. J., R. A. Vincent, M. Tsutsumi, K. Igarashi, Y. Murayama, W. Singer, and D. J. Murphy, 2007: Polar mesosphere and lower thermosphere dynamics: 1. Mean wind and gravity wave climatologies, J. Geophys. Res., 112, D17104, doi:10.1029/2006JD008126.

Eckermann, S. D., D. K. Rajopadhyaya, and R. A. Vincent, 1997: Intraseasonal wind variability in the equatorial mesosphere and lower thermosphere: long-term observations from the central Pacific, J. Atmos. Solar-Terres. Phys., 59(6), 603-627, doi:10.1016/S13646826(96)00143-5.

Farrell, B., 1988: Optimal excitation of neutral Rossby waves, J. Atmos. Sci., 45, 163-172.

Farrell, B. F., and P. J. Ioannou, 1992: Generalized stability theory. Part I: Autonomous operators, J. Atmos. Sci., 53, 2025-2040.

Forbes, J. M., 1995: Tidal and Planetary Waves, The Upper Mesosphere and Lower Thermosphere: A Review of Experiment and Theory, R. M. Johnson and T. L. Killeen, Eds., Geophysical Monograph 87, 67-87.

Forbes, J. M., M. E. Hagan, S. Miyahara, F. Vial, A. H. Manson, C. E. Meek, and Y. Portnyagin, Quasi 16-day oscillation in the mesosphere and lower thermosphere, J. Geophys. Res., 100, 9149-9163, 1995.

Fraser, G. J., Y. I. Portnyagin, J. M. Forbes, R. A. Vincent, I. A. Lysenko, and N. A. Makarov (1995), Diurnal tide in the Antarctic and Arctic mesosphere/lower thermosphere regions, J. Atmos. Terr. Phys., 57, 383-393.

Fritts, D. C., D. Janches, H. Iimura, W. K. Hocking, N. J. Mitchell, B. Fuller, B. Vandepeer, J. 
Hormaechea, C. Brunini, and H. Levato, 2010: Southern Argentina agile meteor radar (SAAMER): System design and initial measurements of large-scale winds and tides, J.

Geophys. Res., 115, D18112, doi:10.1029/2010JD013850.

Hervig, M., and D. Siskind, 2006: Decadal and inter-hemispheric variability in polar mesospheric clouds, water vapor, and temperature, J. Atmos. Solar-Terres. Phys., 68(1), 3041.

Hirooka, T., and I. Hirota (1985), Normal Mode Rossby Waves Observed in the Upper Stratosphere. Part II: Second Antisymmetric and Symmetric Modes of Zonal Wavenumbers 1 and 2. Journal of Atmospheric Sciences, vol. 42,Issue 6, pp.536-548.

Huaman, M. M., and B. B. Balsley, 1999: Differences in near-mesopause summer winds, temperatures, and water vapor at northern and southern latitudes as possible causal factors for inter-hemispheric PMSE differences, Geophys. Res. Lett., 26(11), 1529-1532.

Huang, F. T., H. G. Mayr, C. A. Reber, J. Russell, M. Mlynczak, and J. Mengel (2006), Zonalmean temperature variations inferred from SABER measurements on TIMED compared with UARS observations, J. Geophys. Res. (Space Physics), 111, 10-+, doi: 10.1029/2005JA011427.

Iimura, H., D. C. Fritts, Q. Wu, W. R. Skinner, and SD. E. Palo, 2010: Nonmigrating semidiurnal tide over the Arctic determined from TIMED Doppler Interferometer wind observations, J. Geophys. Res., 115, D06109, doi:10.1029/2009JD012733.

Iimura, H., D. C. Fritts, M. Tsutsumi, T. Nakamura, P. Hoffman, and W. Singer, 2011: Longterm observations of the wind fields in the Arctic and Antarctic mesosphere and lower thermosphere at conjugate latitudes, J. Geophys. Res., submitted.

Isoda, F., T. Tsuda, T. Nakamura, Y. Murayama, K. Igarashi, R.A. Vincent, I.M. Reed, A. 
Nuryanto, S.L. Manurung, 2002, Long-period wind oscillations in the mesosphere and lower thermosphere at Yamagawa $\left(32^{\circ} \mathrm{N}, 131^{\circ} \mathrm{E}\right)$, Pontianak $\left(0^{\circ} \mathrm{N}, 109^{\circ} \mathrm{E}\right)$ and Christmas Island $\left(2^{\circ} \mathrm{N}, 157^{\circ} \mathrm{W}\right)$. , J. Atmos. Sol.-Terr. Phys., 64, 1055-1067.

Kishore, P., S. P. Namboothiri, K. Igarashi, Y. Murayama, R. A. Vincent, A. Dowdy, D. J. Murphy, and B. J. Watkins (2003), Further evidence of hemispheric differences in the MLT mean wind climatology: Simultaneous MF radar observations at Poker Flat $\left(65^{\circ} \mathrm{N}, 147 \circ \mathrm{W}\right)$ and Davis $(69 \circ \mathrm{S}, 78 \circ \mathrm{E})$, Geophys. Res. Lett., , 30(6), 060,000-1, doi:10.1029/2002GL016750.

Luo, Y., A. H. Manson, C. E. Meek, K. Igarashi, and Ch. Jacobi, 2001: Extra long period (20-40 day) oscillations in the mesospheric and lower thermospheric winds: observations in Canada, Europe and Japan, and considerations of possible solar influences, J. Atmos. Solar-Terres. Phys., 63(9), 835-852, doi:10.1016/S1364-6826(00)00206-6.

Luo, Y., Manson, A.H., Meek, C.E., Meyer, C.K., Burrage, M.D., Fritts, D.C., Hall, C.M., Hocking, W.K., MacDougall, J., Riggin, D.M., Vincent, R.A., 2002. The 16-day planetary waves: multi-MF radar observations from the arctic to the equator and comparisons with the HRDI measurements and the GSWM modelling results. Annales Geophysicae 20, 691-709. Madden R. A., P. R. Julian, 1994: Observations of the 40-50-day tropical oscillation - A review, Mon. Wea. Rev., 122, 814-837.

Manney, G. L., M. J. Schwartz, K. Krüger, M. L. Santee, S. Pawson, J. N. Lee, W. H. Daffer, R. A. Fuller, and N. J. Livesey, 2009: Aura microwave limb sounder observations of dynamics and transport during the record-breaking 2009 Arctic stratospheric major warming, J. Geophys. Res., 36, L12815, doi:10.1029/2009GL038586.

Mitchell, N. J., H. R. Middleton, A. G. Beard, P. J. S. Williams, H. G. Muller, 1999: The 16-day 
planetary wave in the mesosphere and lower thermosphere, Ann. Geophys., 17, 1447-1456.

Miyoshi, Y., 1999: Numerical simulation of the 5-day and 16-day waves in the mesopause region, Earth Planets Space, 51, 763-772.

Mukhtarov, P., D. Pancheva, and B. Andonov (2010), Climatology of the stationary planetary waves seen in the SABER/TIMED temperatures (2002-2007), J. Geophys. Res. (Space Physics), 115, 6315-+, doi:10.1029/2009JA015156.

Murphy, D.J., W. J. R. French, R.A. Vincent, 2007: Long-period planetary waves in the mesosphere and lower thermosphere above Davis, J. Atmos. Sol.-Terr. Phys., 69, 2118-2138.

Oberheide J., Q. Wu, T. L. Killeen, M. E. Hagan, R. G. Roble (2006), Diurnal nonmigrating tides from TIMED Doppler Interferometer wind data: Monthly climatologies and seasonal variations, J. Geophys. Res., 111, A10S03, doi:10.1029/2005JA011491.

Portnyagin, Y. I., J. M. Forbes, G. M. Fraser, R. A. Vincent, S. K. Avery, I. A. Lysenko, and N. A. Makarov (1993a), Dynamics of the Antarctic and Arctic mesosphere and lower thermosphere regions-I. The prevailing wind, J. Atmos. Terr. Phys., 55, 827-841.

Portnyagin, Y. I., J. M. Forbes, G. M. Fraser, R. A. Vincent, S. K. Avery, I. A. Lysenko, and N. A. Makarov (1993b), Dynamics of the Antarctic and Arctic mesosphere and lower thermosphere regions-II. The semidiurnal tide, J. Atmos. Terr. Phys., 55, 843-855.

Portnyagin, Yu., et al., 2004: Mesosphere/lower thermosphere prevailing wind model, Adv. Space Res., 34(8), 2004, 1755-1762.

Portnyagin, Yu. I., E. G. Merzlyakov, T. V. Solovs'eva, and N. A. Makarov, 2006: Interhemispheric distinctions in wind-regime parameters in the polar mesosphere-lower thermosphere, Izvesiya AN. Fizika Atmosfery i Okeana, 42(1), 102-114. 
Randel, W. J., D. R. Stevens, and J. L. Stanford, 1987: A study of planetary waves in the Southern winter troposphere and stratosphere. Part II: Life cycles, J. Atmos. Sci., 44, 936949.

Riggin, D. M., H.-L. Liu, R. S. Lieberman, R. G. Roble, J. M. Russell III, C. J. Mertens, M. G. Mlynczak, D. Pancheva, S. J. Franke, Y. Murayama, A. H. Manson, C. E. Meek, and R. A. Vincent, 2006: Observations of the 5-day wave in the mesosphere and lower thermosphere, J. Atmos. Solar-Terres. Phys., 68(3-5), 323-339.

Riggin, D. M., C. K. Meyer, D. C. Fritts, M. J. Jarvis, Y. Murayama, W. Singer, R. A. Vincent, and D. J. Murphy (2003), MF radar observations of seasonal variability of semidiurnal motions in the mesosphere at high northern and southern latitudes, J. Atmos. Sol. Terr. Phys., 65, 483-493, doi:10.1016/S1364-6826(02)00340-1.

Salby, M. L., 1981a: Rossby Normal Modes in Nonuniform Background Configurations. Part I: Simple fields, J. Atmos. Sci., 38, 1803-1826.

Salby, M. L., 1981b: Rossby Normal Modes in Nonuniform Background Configurations. Part II: Equinox and Solstice Conditions, J. Atmos. Sci., 38, 1827-1840.

Simmons, A. J., B. J. Hoskins, and D. M. Burridge (1978), Stability of the semi-implicit method of time integration, Mon. Weather Rev., 106, 405-412.

Singer, W., J. Bremer, J. Weiß, W.K. Hocking, J. Höffner, M. Donner, P. Espy, 2004a, Meteor radar observations at middle and Arctic latitudes Part 1: mean temperatures., J. Atmos. Sol.Terr. Phys., 66, 607-616. 
Singer, W., J. Bremer, W.K. Hocking, J. Weiss, R. Latteck, M. Zecha, 2003, Temperature and wind tides around the summer mesopause at middle and arctic latitudes., Adv. Space Res., Vol. 31, No. 9, pp. 2055-2060, doi: 10.1016/S0273-1177(03)00228-X.

Singer, W., H. Iimura, D. C. Fritts, and D. Janches, 2011: A Conjugate Study of tides employing enhanced meteor radars at Rio Grande, Argentina $\left(53.8^{\circ} \mathrm{S}\right)$ and Juliusruh, Germany $\left(54.6^{\circ} \mathrm{N}\right)$, J. Geophys., Res., to be submitted.

Singer, W., R. Latteck, P. Hoffmann, B. P. Williams, D. C. Fritts, Y. Murayama, and K. Sakanoi, 2005, Tides near the Arctic summer mesopause during the MaCWAVE/MIDAS summer program, Geophys. Res. Lett., 32, L07S90, doi:10.1029/2004GL021607.

Singer, W., J. Weiß, and U. von Zahn, 2004b, Diurnal and annual variations of meteor rates at the arctic circle, Atmos. Chem. Phys., 4, 1355-1363.

Siskind, D. E., S. D. Eckermann, J. P. McCormack, M. J. Alexander, and J. T. Bacmeister, 2003: Hemispheric differences in the temperature of the summertime stratosphere and mesosphere, J. Geophys. Res., 108(D2), 4051, doi:10.1029/2002JD002095.

Smith, A. K., 1985: Wave transience and wave-mean flow interaction caused by the interference of stationary and traveling waves, J. Atmos. Sci., 42, 529-535.

Smith, A. K., 2003: The origins of stationary planetary waves in the upper mesosphere, American Meteorological Society, 3033-3041.

Stockwell, R. G., L. Mansinha, and R. Lowe (1996), Localization of the complex spectrum: The S transform, IEEE Trans. Signal Process., 44(4), 998 - 1001.

Szasz, C., J. Kero, A. Pellinen-Wannberg, J.D. Matthews, N.J. Mitchell, W. Singer, 2004, Latitudinal variations of diurnal meteor rates., Earth, Moon, and Planets, 95, 101-107, DOI 10.1007/s11038-005-9007-0. 
Vial, F., 1989: Tides in the middpe atmosphere, J. Atmos. Terres. Phys., 51(1), 3-17.

Vincent, R. A., T. Tsuda, and S. Kato, 1988: A Comparative Study of Mesospheric Solar Tides Observed at Adelaide and Kyoto, J. Geophys. Res., 93(D1), 699-708.

Volland, H., 1988: Atmospheric Tidal and Planetary Waves, Kluwer Academic Publ., Boston, MA.

Williams, C. R. and S. K. Avery, 1992: Analysis of long-period waves using the mesospherestratosphere-troposphere radar at poker flats, Alaska, J. Geophys. Res., 97, 20855-20861.

Xu, J., A. K. Smith, W. Yuan, H.-L. Liu, Q. Wu, M. G. Mlynczak, and J. M. Russell III, 2007a: Global structure and long-term variations of zonal mean temperature observed by TIMED/SABER, J. Geophys. Res., 112, D24106, doi:10.1029/2007JD008546.

Xu, J., H.-L. Liu, W. Yuan, A. K. Smith, R. G. Roble, C. J. Mertens, J. M. Russell III, and M. G. Mlynczak, 2007b: Mesopause structure from Thermosphere, Ionosphere, Mesosphere, Energetics, and Dynamics (TIMED)/Sounding of the Atmosphere Using Broadband Emission Radiometry (SABER) observations J. Geophys. Res., 112, D09102, doi:10.1029/2006JD007711.

\section{Figure captions}

Figure 1. Time-height displays of 2-day mean (a and c) zonal and (b and d) meridional winds over (a and b) JLR and (c and d) TdF from June 2008 through May 2010.

Figure 2. As in Figure 1, but for 30-day means at 5-day intervals.

Figure 3. S-transforms as functions of time and period of 2-day mean (a, b, e, and f) zonal and (c, d, g, and h) meridional winds at (a, c, e, and g) 84 and (b, d, f, and h) $96 \mathrm{~km}$ for (a-d) JLR and 
(e-h) TdF from June 2008 through May 2010. Note the clear seasonal variations and consistency between the zonal and meridional motions over JLR, and the lack of clear seasonal variations and consistency between the zonal and meridional motions over TdF.

Figure 4. S-transform amplitudes as functions of time and altitude for periods of ( $a, b, i$, and $j$ ) 10, (c, d, k, and l) 16, (e, f, m, and n) 20, and (g, h, o, and p) 40 days. Left (right) panels show the zonal (meridional) components, respectively.

Figure 5. Time-height displays of ( $a$ and $c$ ) zonal and ( $b$ and $d$ ) meridional 7-12 day band-pass winds over ( $a$ and b) JLR and (c and d) TdF from June 2008 through May 2010.

Figure 6. Band pass winds at 3-km intervals from 81 to $96 \mathrm{~km}$ over (a-d) JLR and (e and f) TdF. Band passes are (a, b, and e) 7-12 days and (c, d, and f) 12-24 days. Intervals are (a and c) October 2008 to March 2009, (b and d) October 2009 to March 2010, and (e and f) June 2008 to May 2010. Red and blue denote zonal and meridional winds, respectively.

Figure 7. As in Figure 5, but for 12-24 day band pass winds.

Figure 8. Hodographs of monthly 7-12 day band pass winds over (a and b) JLR and (c and d) TdF. Intervals are (a) October 2008 to March 2009, (b) October 2009 to March 2010, (c) April to October 2008, and (d) April to October 2009. Blue (red) indicates the first (last) day in each month.

Figure 9. As in Figure 8, but for monthly 12-24 day band pass winds.

Figure 10. Horizontal wind variances as functions of time and altitude for band passes of (a and e) 7-12 days and (c and g) 12-24 days over (a and c) JLR and (e and g) TdF. (b, d, f, and h) Same as in (a, c, e, and g), but for horizontal momentum fluxes $\left\langle\mathrm{u}^{\prime} v^{\prime}>\right.$. 
Figures
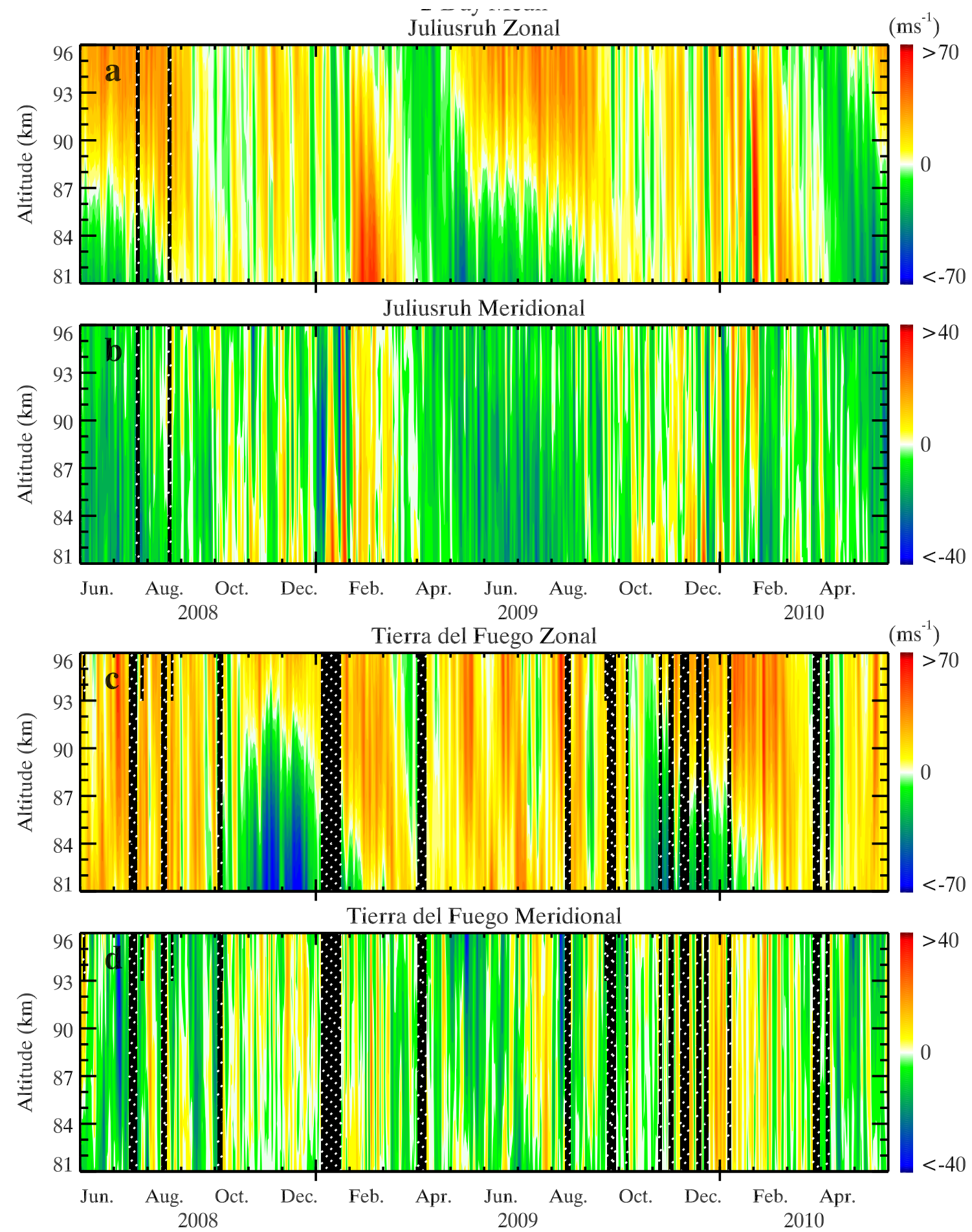

Figure 1. Time-height displays of 2-day mean ( $a$ and $c$ ) zonal and ( $b$ and d) meridional winds over (a and b) JLR and (c and d) TdF from June 2008 through May 2010. 
Monthly Mean

Juliusruh Zonal

$\left(\mathrm{ms}^{-1}\right)$
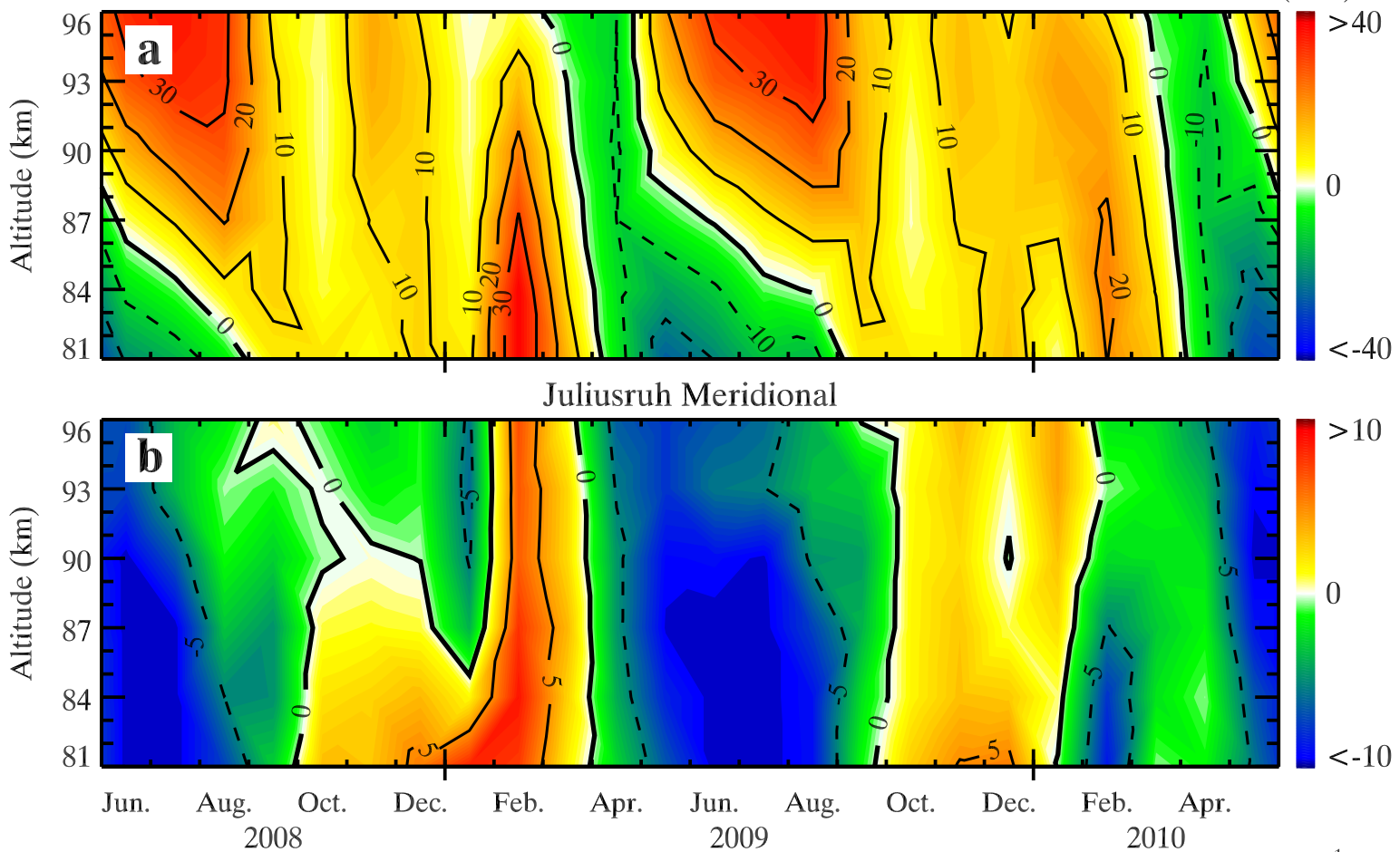

Tierra del Fuego Zonal

$\left(\mathrm{ms}^{-1}\right)$

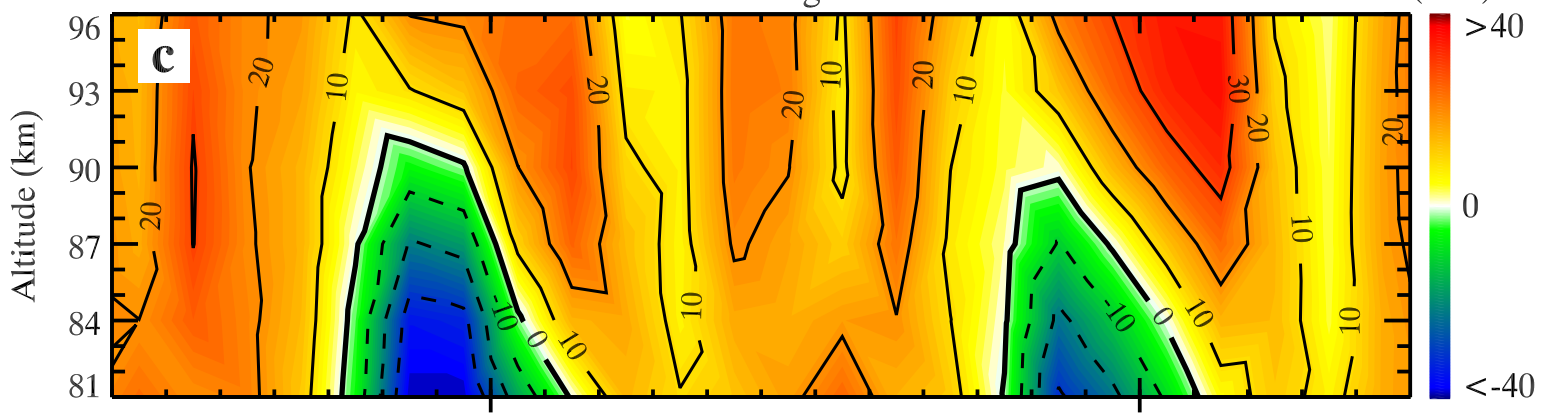

Tierra del Fuego Meridional

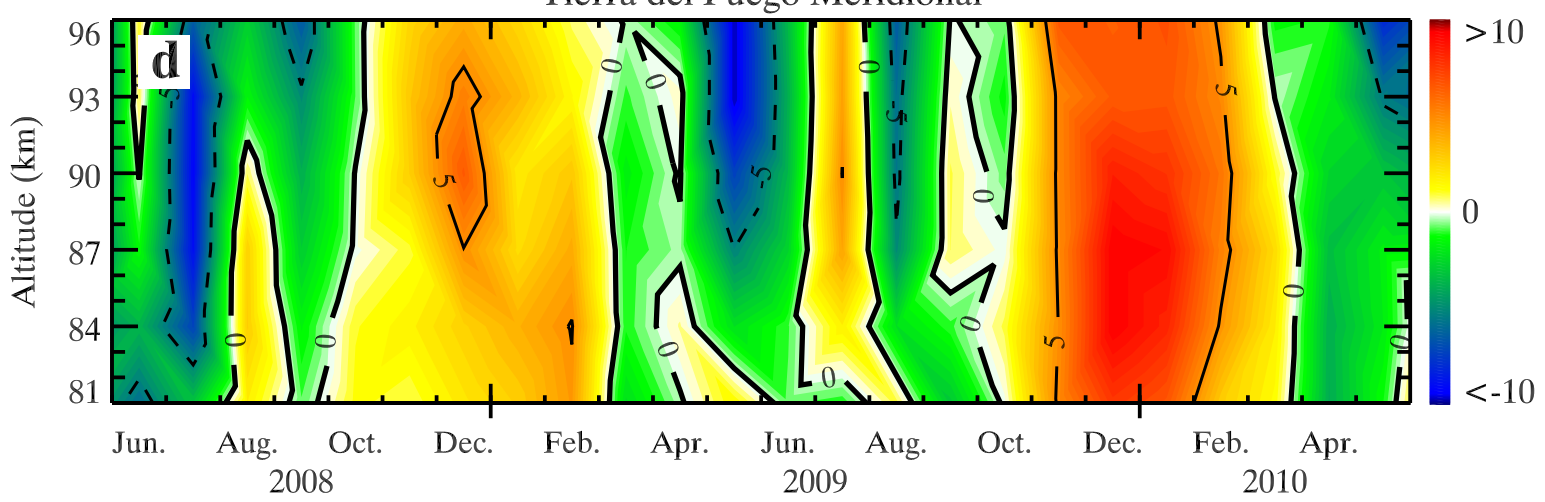

Figure 2. As in Figure 1, but for 30-day means at 5-day intervals. 

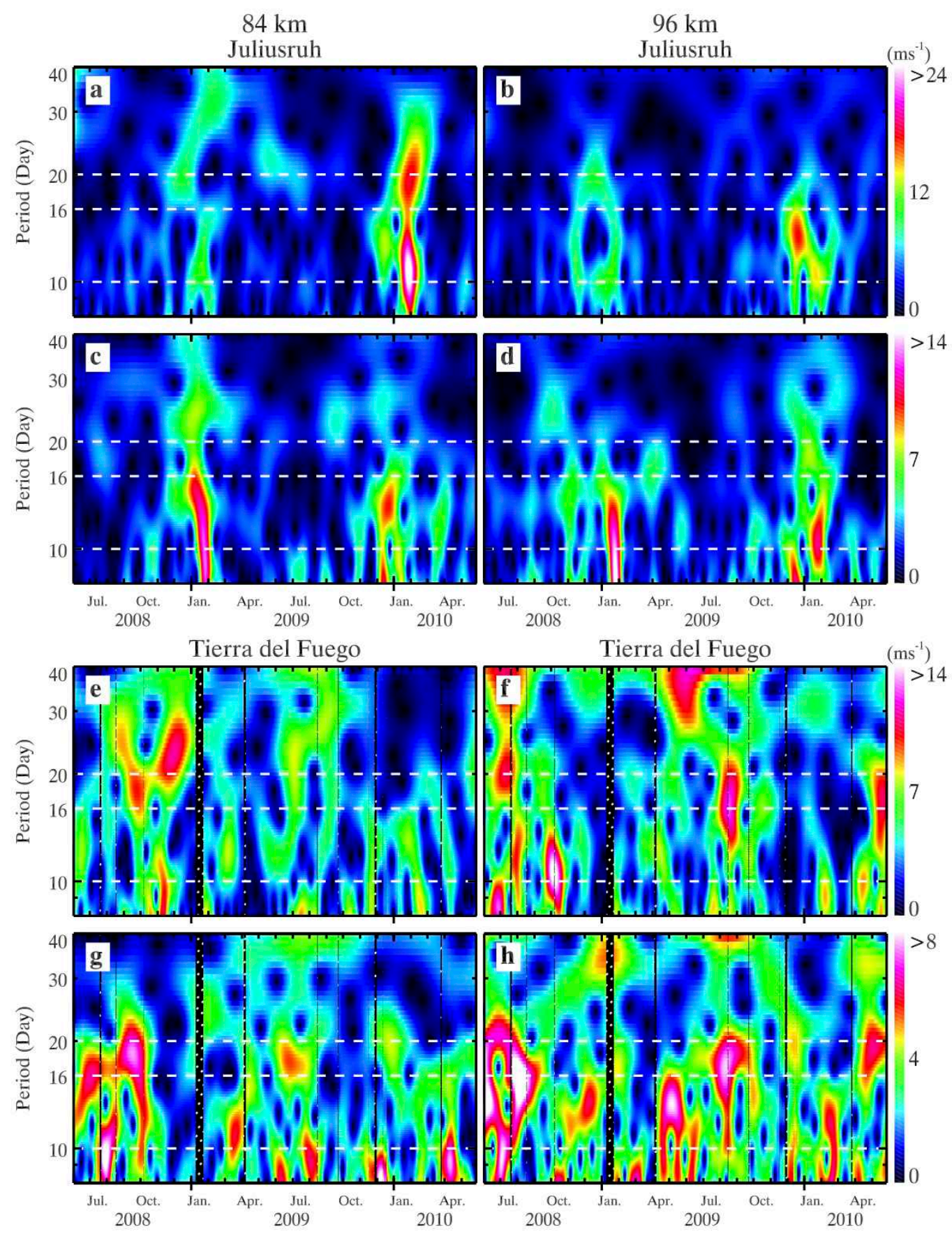

Figure 3. S-transforms as functions of time and period of 2-day mean (a, b, e, and f) zonal and (c, d, g, and h) meridional winds at (a, c, e, and g) 84 and (b, d, f, and h) $96 \mathrm{~km}$ for (a-d) JLR and (e-h) TdF from June 2008 through May 2010. Note the clear seasonal variations and consistency between the zonal and meridional motions over JLR, and the lack of clear seasonal variations and consistency between the zonal and meridional motions over TdF. 

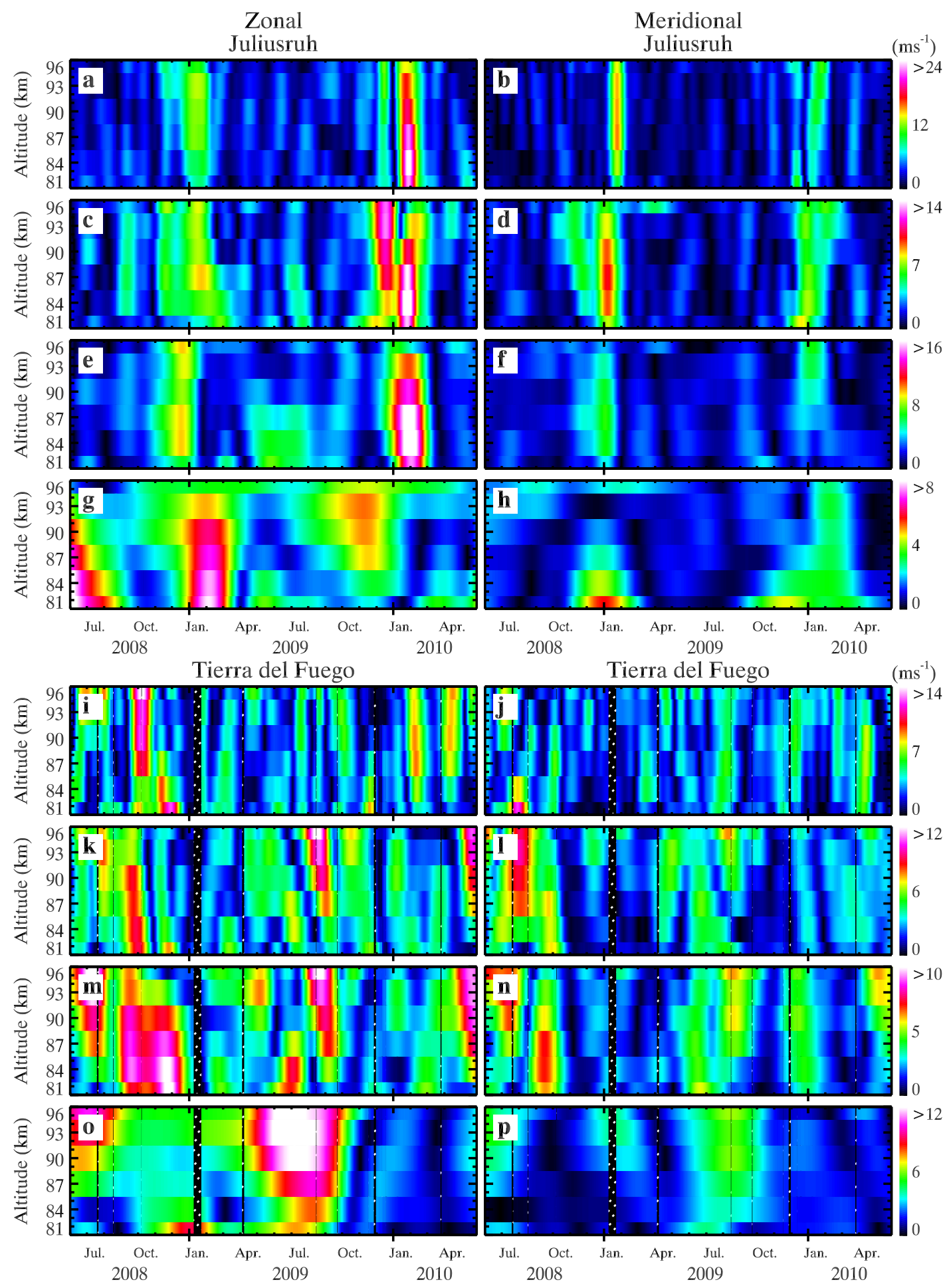

Figure 4. S-transform amplitudes as functions of time and altitude for periods of (a, b, i, and j)

10, (c, d, k, and l) 16, (e, f, m, and n) 20, and (g, h, o, and p) 40 days. Left (right) panels show the zonal (meridional) components, respectively. 

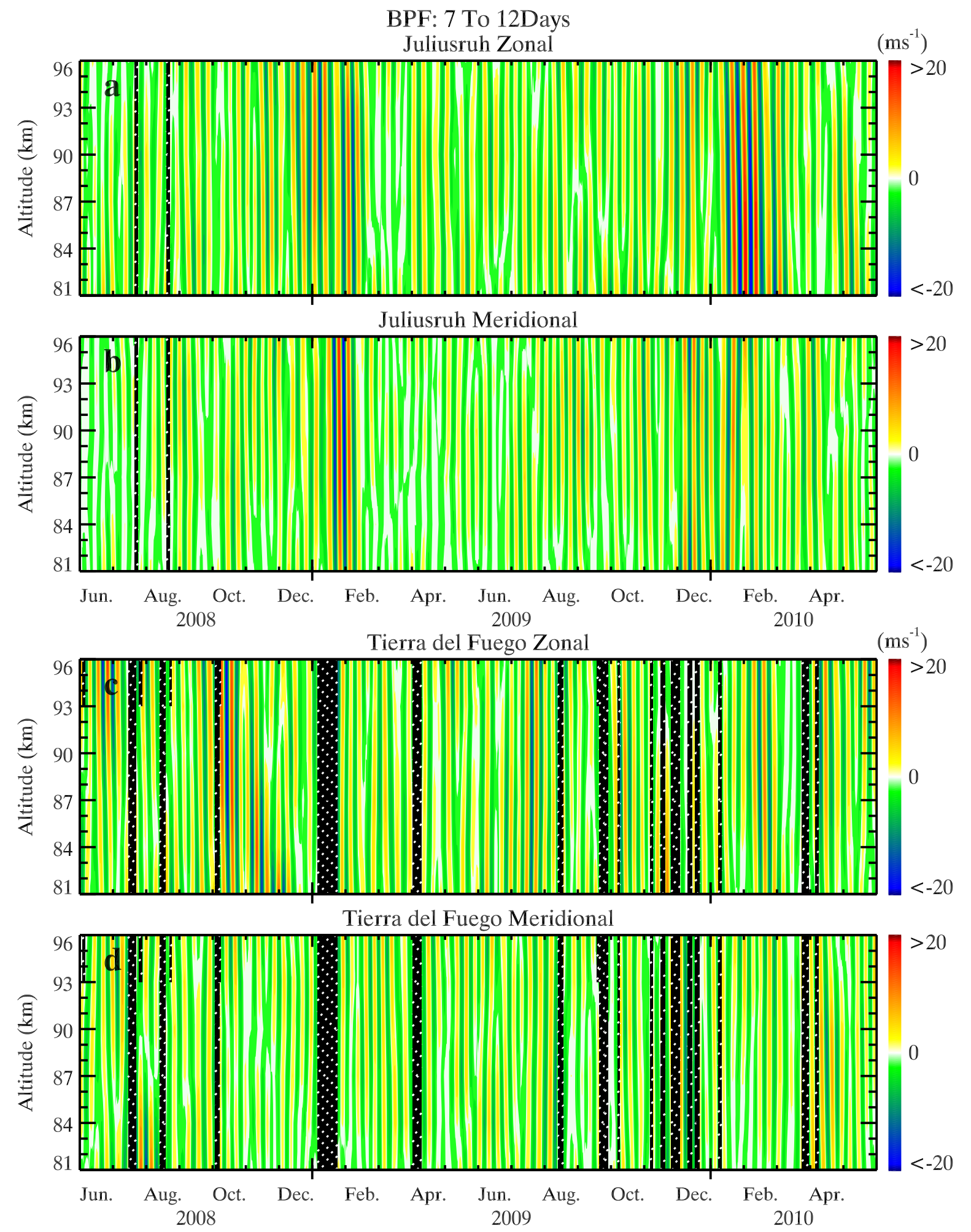

Figure 5. Time-height displays of ( $a$ and $c$ ) zonal and ( $b$ and d) meridional 7-12 day band-pass winds over ( $a$ and b) JLR and (c and d) TdF from June 2008 through May 2010. 

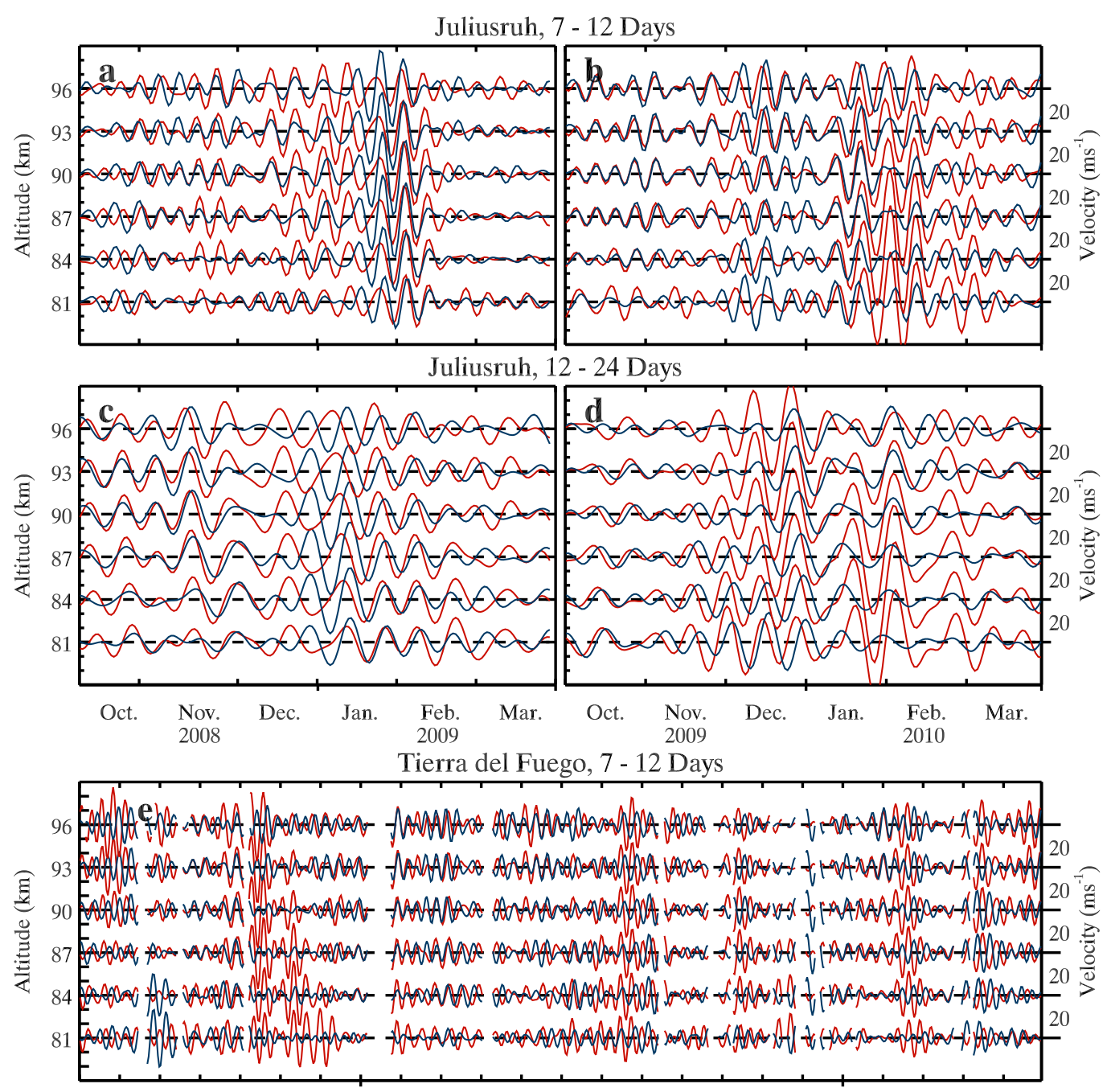

Tierra del Fuego, 12 - 24 Days

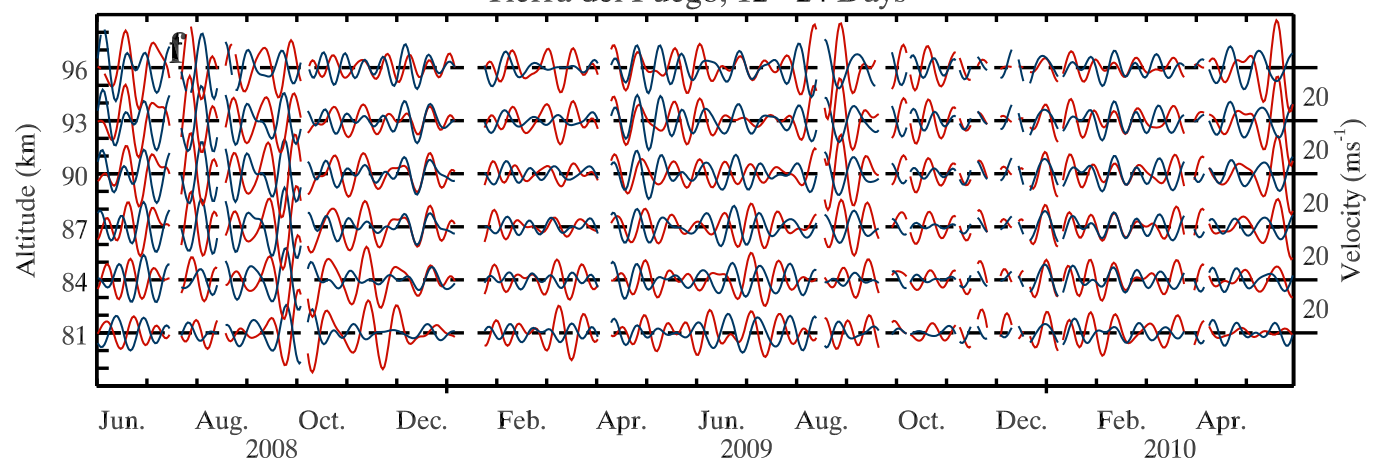

Figure 6. Band pass winds at 3-km intervals from 81 to $96 \mathrm{~km}$ over (a-d) JLR and (e and f) TdF.

Band passes are (a, b, and e) 7-12 days and (c, d, and f) 12-24 days. Intervals are (a and c)

October 2008 to March 2009, (b and d) October 2009 to March 2010, and (e and f) June 2008 to

May 2010. Red and blue denote zonal and meridional winds, respectively. 

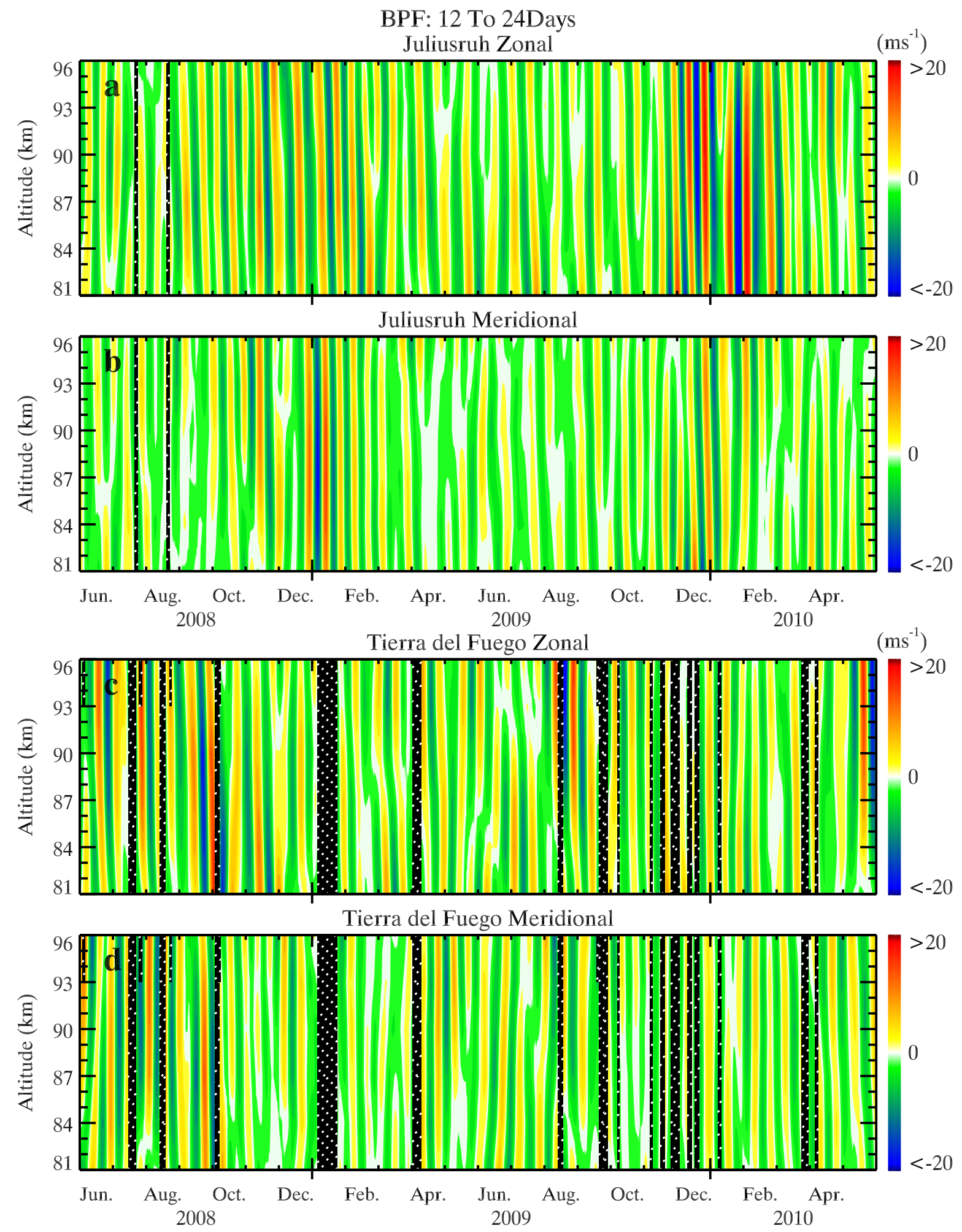

Figure 7. As in Figure 5, but for 12-24 day band pass winds. 


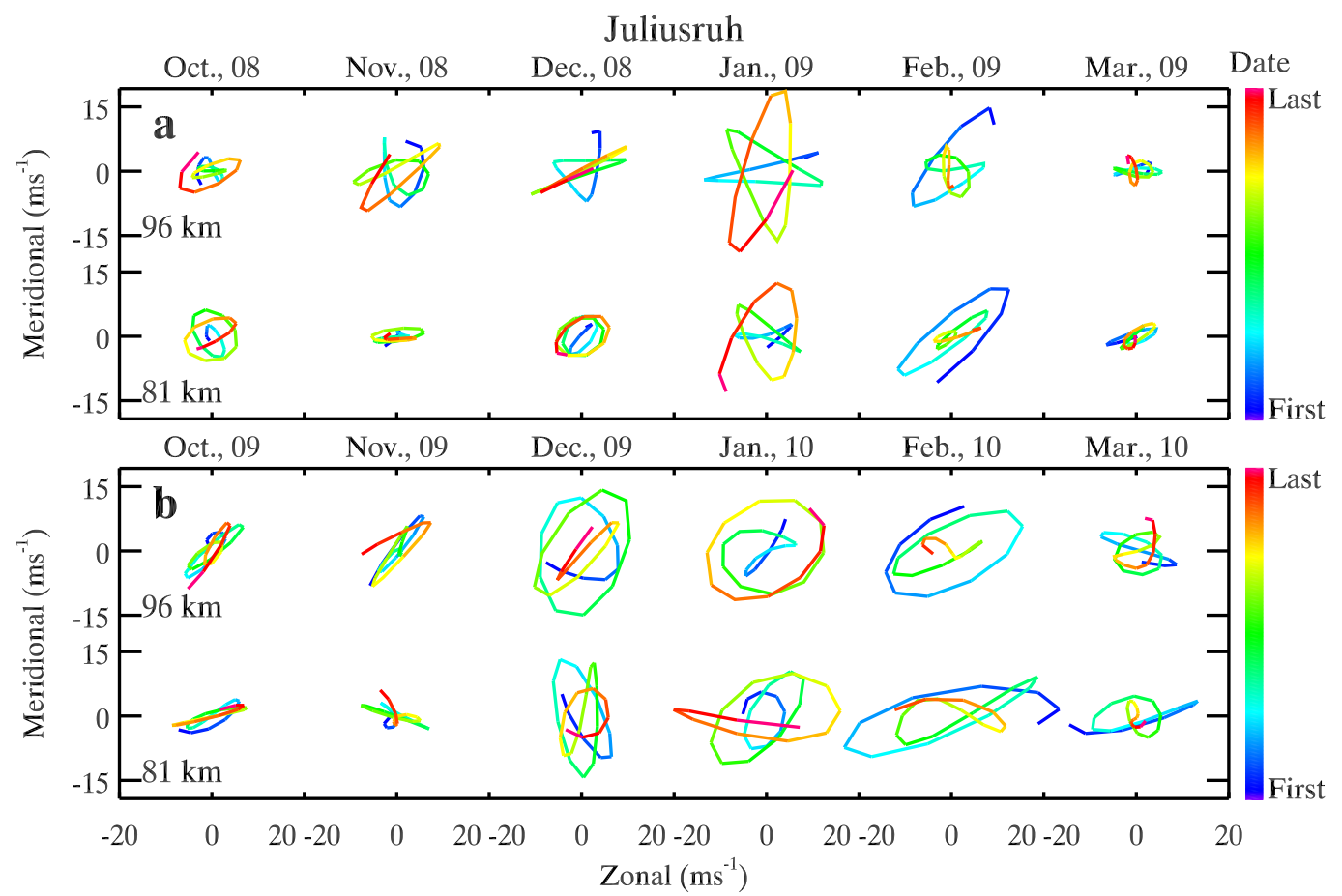

Tierra del Fuego
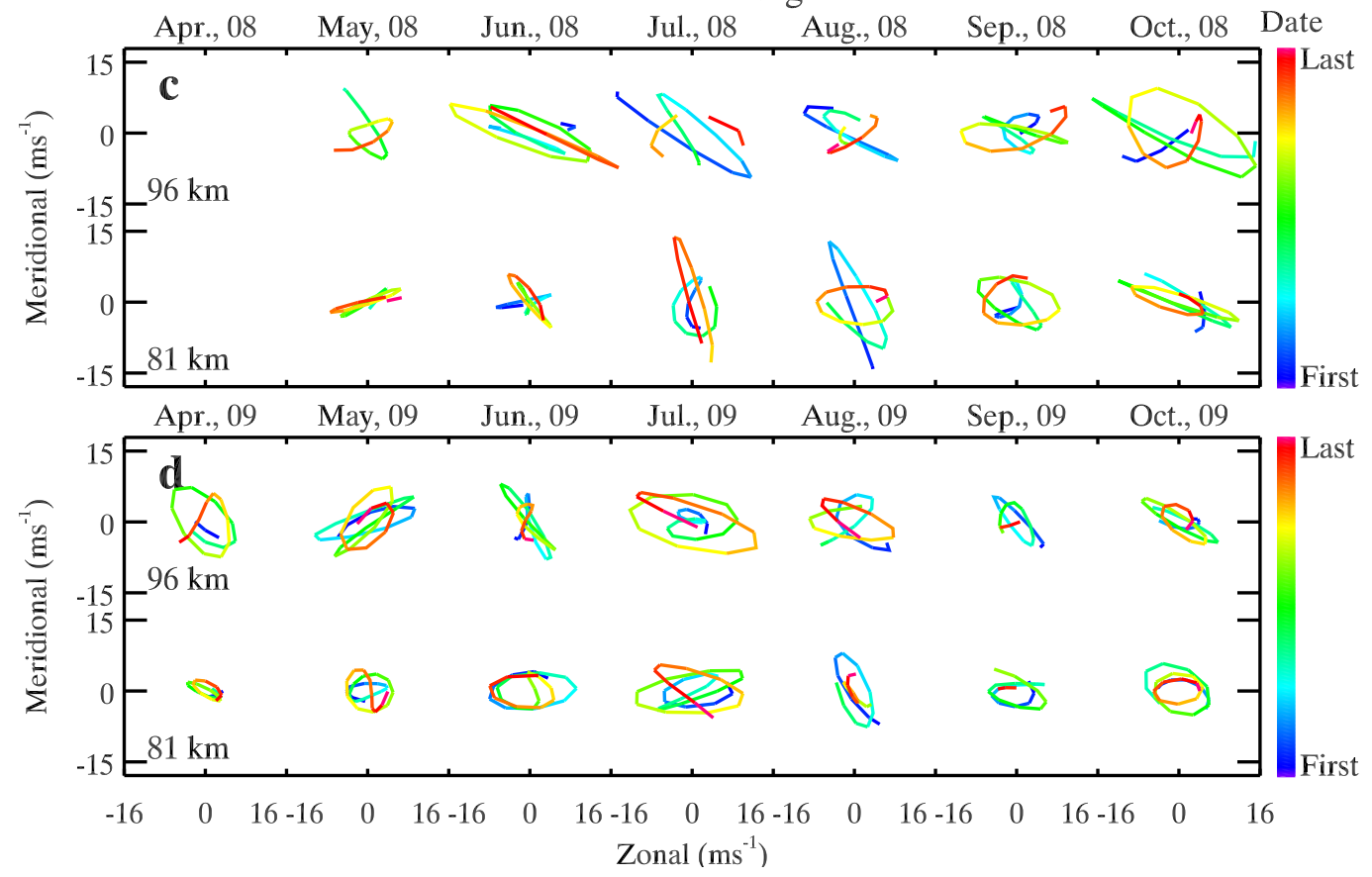

Figure 8. Hodographs of monthly 7-12 day band pass winds over (a and b) JLR and (c and d) TdF. Intervals are (a) October 2008 to March 2009, (b) October 2009 to March 2010, (c) April to October 2008, and (d) April to October 2009. Blue (red) indicates the first (last) day in each month. 


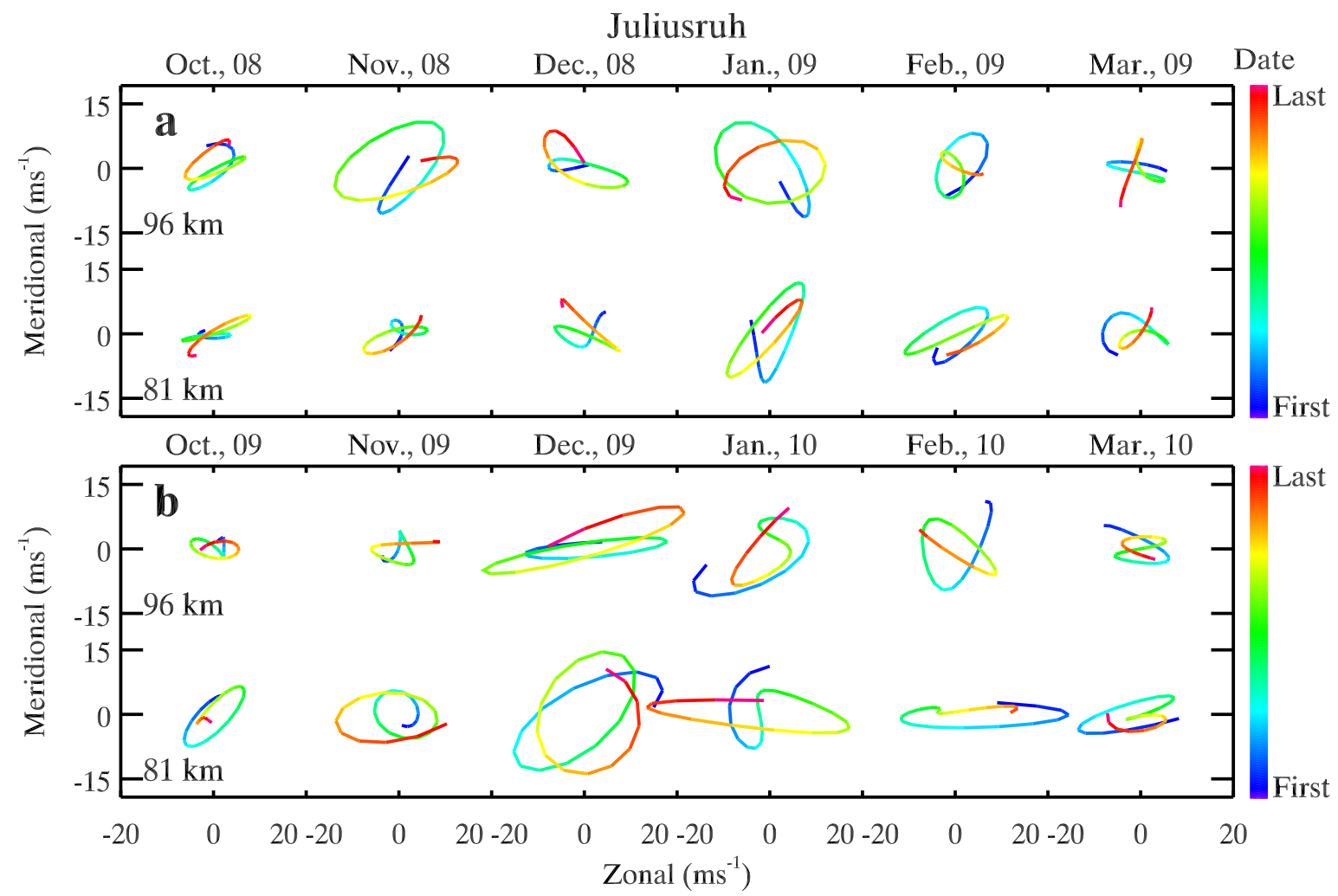

Tierra del Fuego
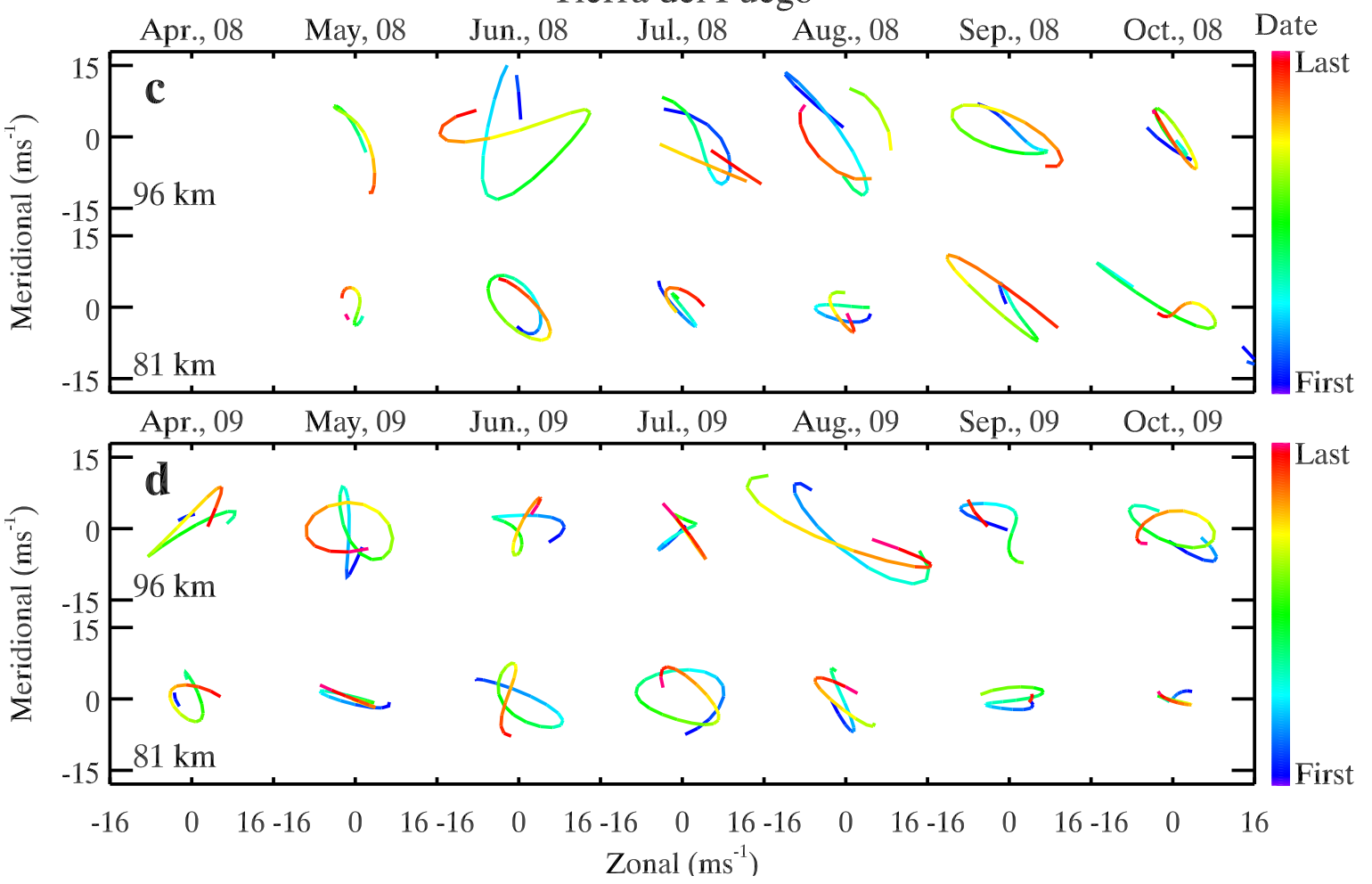

Figure 9. As in Figure 8, but for monthly 12-24 day band pass winds. 

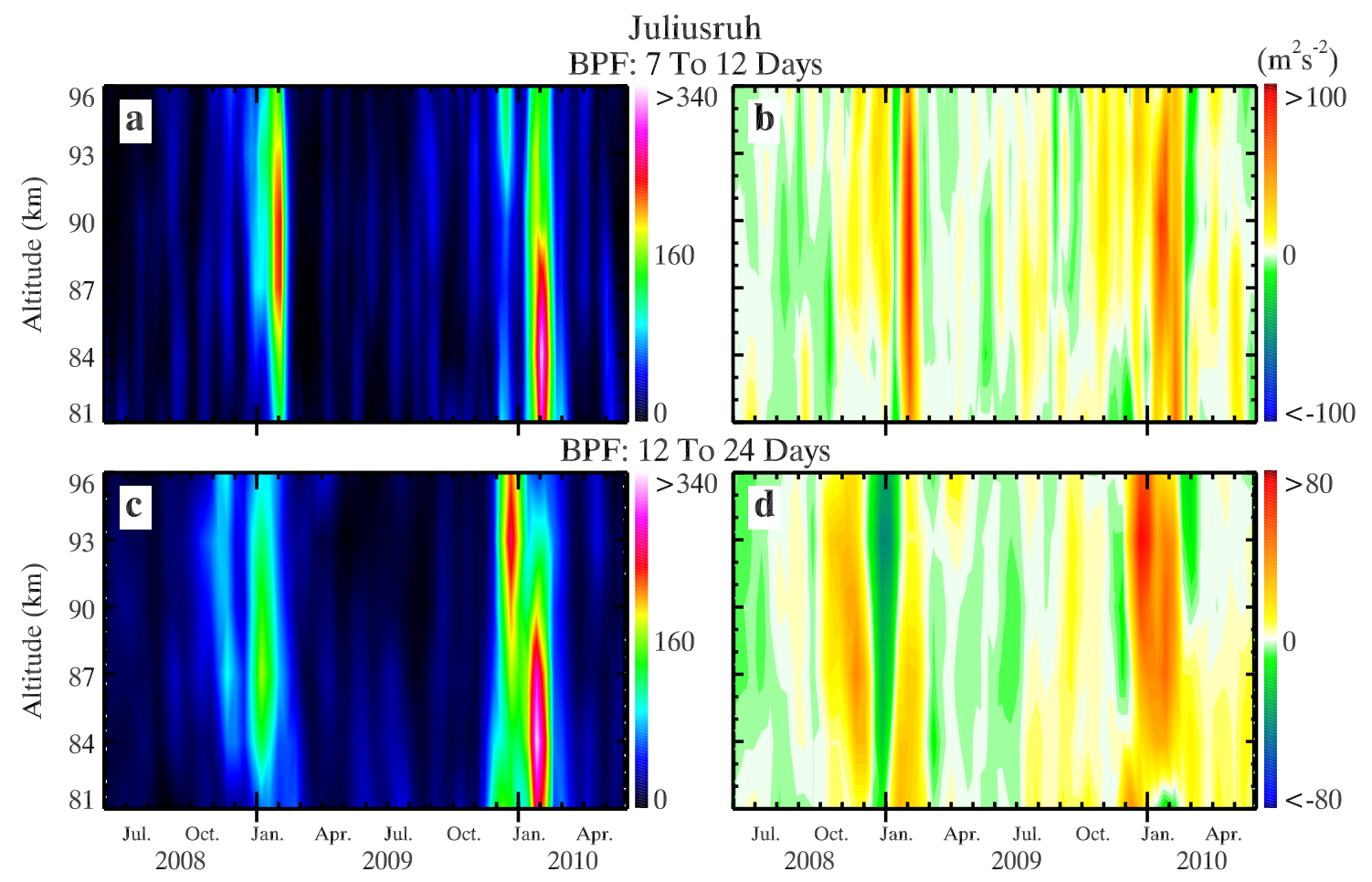

Tierra del Fuego

BPF: 7 To 12 Days
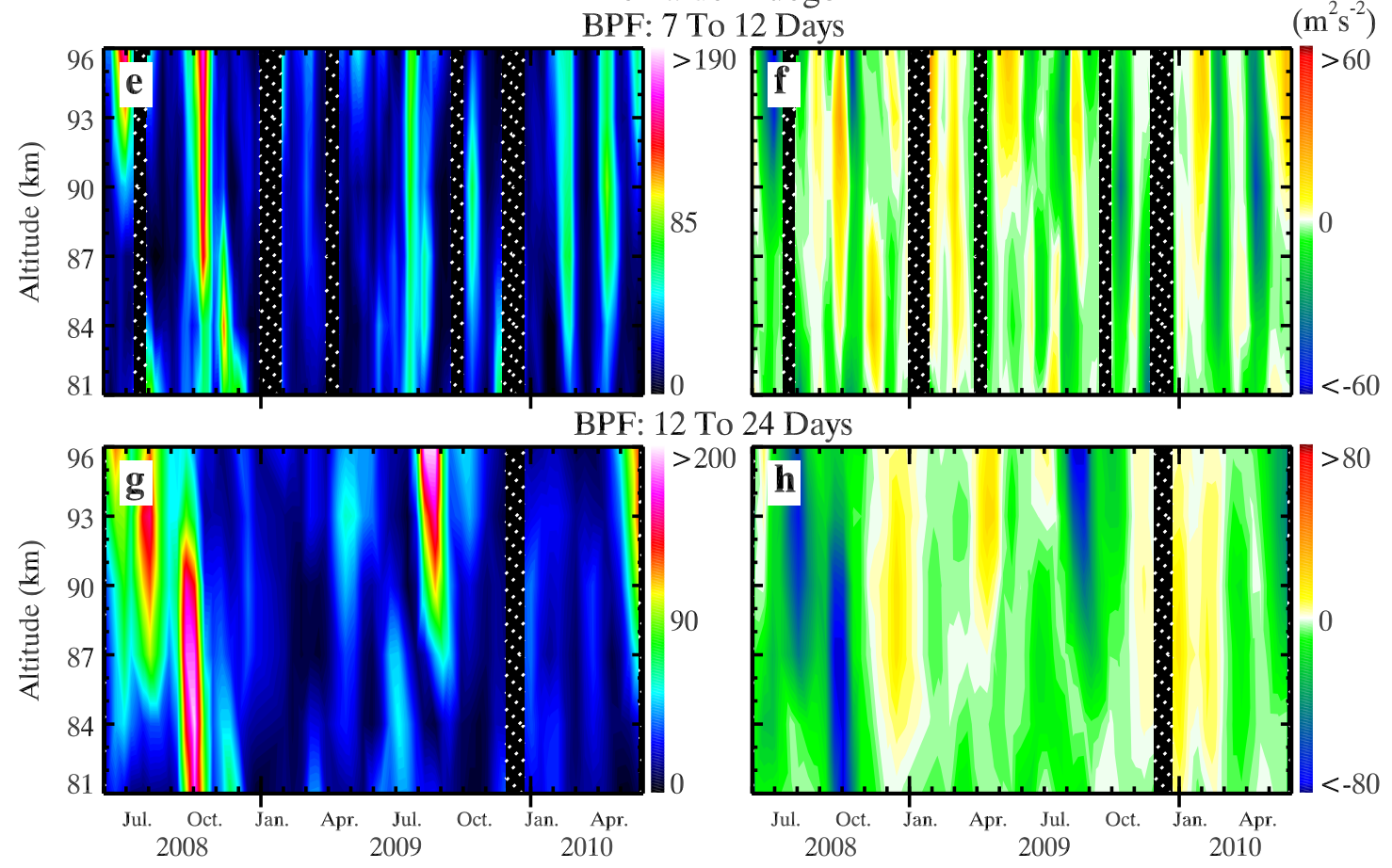

Figure 10. Horizontal wind variances as functions of time and altitude for band passes of (a and

e) 7-12 days and (c and g) 12-24 days over (a and c) JLR and (e and g) TdF. (b, d, f, and h) Same as in (a, c, e, and g), but for horizontal momentum fluxes $<\mathrm{u}^{\prime} \mathrm{v}^{\prime}>$. 